\title{
Nuevas aproximaciones para el análisis de sistemas de protección social: La noción de desempeño institucional y su aplicación al sistema de pensiones chileno
}

\author{
Aldo Madariaga Espinoza \\ Sociólogo, Universidad de Chile \\ aldomadariaga@gmail.com \\ Nicolás Pérez Morgado \\ Licenciado en sociología, Universidad de Chile. \\ nperezm@gmail.com
}

Resumen

El sistema de pensiones de capitalización individual en Chile constituye un ejemplo paradigmático de las transformaciones llevadas a cabo en los sistemas de seguridad social en los años ochenta en los países de América Latina y en todo el mundo en desarrollo. Al cabo de un cuarto de siglo de su implantación este fue seriamente cuestionado respecto de su impacto en los elementos considerados sus grandes fortalezas, lo que derivó en una reforma que introduce avances importantes en la protección de los y las más vulnerables. No obstante ello, la estructura y los principios fundantes del sistema se mantienen en gran medida intactos. Se plantea la existencia de un déficit a nivel conceptual y metodológico como una de las principales piedras de tope que ha influido en el fracaso de estos sistemas y sus reformas. El presente trabajo propone la necesidad de reconstruir el aparataje conceptual y analítico utilizado por las ciencias sociales para dar cuenta de los problemas sociales y de las dinámicas de protección que ponen en movimiento los sistemas de pensiones en tanto mecanismos de protección social. Los conceptos y relaciones propuestas son aplicados exploratoriamente al análisis del desempeño para el caso del sistema de pensiones chileno, proponiendo una estrategia metodológica denominada "análisis de desempeño institucional".

\section{Abstract}

The pension system of individual capitalization in Chile is an example of the transformations carried out in social security systems in the eighties, in Latin America and throughout the developing world. After a quarter century of its introduction this was seriously questioned regarding their impact on the elements considered his greatest strengths, which resulted in a reform that makes significant progress in the protection of the most vulnerable. However, the structure and the founding principles of the system remain largely intact. Posed the existence of a deficit at the conceptual and methodological approach as a major stumbling block that has influenced the failure of these systems and their reforms. This paper proposes the need to reconstruct the conceptual and analytical apparatus used by social scientists to account for social problems and the dynamics of protection set in motion the pension systems as social protection mechanisms. The concepts and relationships proposed are applied to exploratory analysis of performance for the case of the Chilean pension system, proposing a methodological strategy called "analysis of institutional performance." 
Nuevas aproximaciones para el análisis de sistemas de protección social: La noción de desempeño institucional y su aplicación al sistema de pensiones chileno

Palabras Clave: Sistema de pensiones , protección social, capitalización individual, desempeño institucional, Chile

Keywords: Pension system, social protection, individual capitalization, institutional performance, Chile

\section{Introducción}

A principios de la década de los 80' Chile fue pionero en llevar a cabo un cambio de paradigma en la política social a partir de la transformación de sus sistemas de seguridad social que significó, grosso modo, la privatización de esta y el traspaso de la gestión de los riesgos a los propios individuos. El diagnóstico que impulsó estas reformas atribuía el fracaso de los antiguos esquemas a diversos problemas institucionales y de diseño que, acentuados por una acelerada transición demográfica, presionarían sobre el presupuesto fiscal convirtiéndose en una carga insostenible para el Estado en el mediano plazo. La transformación tuvo lugar de manera paradigmática en el sistema de pensiones que, luego de su completa modificación en 1981, pasó a convertirse en la punta de lanza de una concepción neoliberal del Estado y una estrategia de política social de tipo residual. Esta innovación fue recibida con entusiasmo por los organismos financieros multilaterales que no vacilaron en plantearla como la receta al problema de la seguridad social en América Latina y en otros países en vías de desarrollo. Un ejemplo de ello es el documento del Banco Mundial de inicios de la década del noventa donde recomienda a los países adoptar un sistema de pilares homólogo al de la reforma chilena, independiente de las características demográficas de los países - tasas de dependencia, grado de avance en la transición demográfica-, de sus niveles de desarrollo y de sus características insitucionales. Los ejes principales de este modelo eran un pilar contributivo de ahorro individual para el conjunto de la población, a cargo de administradoras privadas, y un segundo pilar de pensiones asistenciales estatales, altamente focalizado en los más pobres $^{1}$. Bajo el auspicio de estas instituciones, el modelo se expandió con rapidez por la región, llegando a generar tres tipos de variantes en las formas como fue implementado (CEPAL, 2006): modelos sustitutivos, que reemplazaban completamente al sistema anterior (caso original de Chile, Bolivia -1997-, México -1997-, El Salvador 1998-, República Dominicana -2003-2005-), modelos paralelos, en que el nuevo pilar de capitalización compite con el público de reparto (Perú -1993-, Colombia -1994-) y modelos mixtos en que existe la posibilidad de aportar en ambos pilares (Argentina 1994-, Uruguay -1996-, Costa Rica -2001-, Ecuador-2001-).

Es importante destacar que la previsión social, y en particular la protección de la vejez, no son preocupaciones recientes en la historia de América Latina, ni mucho menos en Chile. Por el contrario, luego de los países más desarrollados de Europa y antes incluso que Estados Unidos y Japón, en el cono sur se introdujeron sistemas de seguridad social, principalmente para la protección de la salud y la vejez (Mesa Lago 2004). Junto con países como Uruguay, Argentina, Cuba, Brasil y Costa Rica, Chile representó la vanguardia en temas de seguridad social dentro de Ameríca Latina, al comenzar a conformar entre los decenios de 1920 y 1930 sus primeros mecanismos de seguridad social, mientras que el resto de la región se incorpora a estos desarrollos recién hacia la década de 1970.

El diverso desarrollo económico, social y demográfico en Latinoamérica implicó, y sigue implicando, diferencias importantes en los mecanismos implementados y sus resultados. Los problemas de cobertura (por la existencia de grandes poblaciones de 
difícil acceso) y la particular conformación del mercado del trabajo, que a diferencia de los países desarrollados contiene una gran cantidad de relaciones laborales que dificultan el acceso a la seguridad social tradicional -cuyo mayor reflejo son las altas tasas de trabajo informal- hace que existan desafíos conjuntos en la región (Bertranou, 2001), La reforma chilena de 1981 plantó una salida que significó un desafío a los principios de la seguridad social tradicional (Mesa Lago, 2004), pero que, sin embargo, no terminó de hacerse cargo del particular panorama latinoamericano, el cual sigue manteniendo una baja cobertura y en el cual el rol redistributivo de las pensiones de vejez es sumamente importante para la integración social (Uthoff, 2006)

A cerca de 25 años de la aclamada reforma chilena, las primeras evaluaciones arrojaron serias dudas respecto de la capacidad del sistema de capitalización individual de proveer efectivamente protección social para la vejez. (INP-CENDA, 2005; Berstein, Larraín y Pino, 2005). Además de denunciar los bajos niveles de cobertura, especialmente de trabajadores independientes y de mujeres, y los bajos montos de los beneficios si se los mide como tasa de reemplazo del último salario, estas evaluaciones se encargaron si no de derribar, al menos de poner fuertemente en tela de juicio otros importantes mitos respecto de las bondades del sistema, por ejemplo, evidenciando la alta carga fiscal que habría implicado la transición de un sistema a otro - aun en curso- la progresiva concentración del mercado de administradoras privadas en unas pocas instituciones, y recientemente, la vulnerabilidad que implica la exposición de los fondos a los vaivenes de los flujos de capital y las bolsas internacionales, por nombrar algunos. ${ }^{2}$ Algunas de estas tendencias ya estaban comenzando a visualizarse en algunos de los países que emprendieron las reformas, aunque de manera incipiente dado el rezago con que estas fueron realizadas en comparación con la temprana experiencia chilena.

Los análisis mencionados llevaron a que, así como fue pionero en su implementación, el país se convirtiera también en uno de los primeros en plantear la necesidad de incluir importantes modificaciones. Se creó en este contexto en 2006 una comisión especial compuesta por un panel de expertos encargados de escuchar diversos sectores de la sociedad chilena, académicos, organizaciones sociales, centros de estudios, organismos internacionales, etc. y recoger sus planeamientos para proponer un proyecto de reforma. Finalmente a inicios de 2008 se anunció la aprobación de una nueva legislación cuyas características principales serían la creación de una pensión básica no contributiva para el $60 \%$ de la población más pobre que no lograba cotizar en el sistema (la denominada Pensión Básica Solidaria -PBS-) y aportes complementarios hasta un cierto monto máximo para quienes aun cotizando, conseguían pensiones demasiado bajas (Pensión con Aporte Solidario -PAS-). Ambas constituyen sin duda avances sustanciales en la protección de las personas más vulnerables, especialmente aquellas que no lograban siquiera acceder a la garantía estatal de pensión mínima que equivalían a más de la mitad de los afiliados al sistema (Berstein, Larraín y Pino, 2005; INP-CENDA, 2005).

Más allá de la importancia del establecimiento de niveles mínimos de protección para la vejez relativamente universales, resulta interesante notar que la reforma realizada no cambia el carácter esencial que asume la protección ofrecida por el sistema de pensiones chileno: la provisión privada de bienes públicos y el mercado como regulador de la asignación de la previsión social, la gestión individual de los riesgos asociados a la pérdida de ingresos en la vejez y el rol subsidiario del Estado relegado a cubrir las fallas del mercado. Esto pone serias dudas respecto de la efectividad de la reforma pues no parecen haber sido abordadas las causas que están detrás de los problemas que la motivaron, particularmente, las dificultades que tiene un sistema de 
pensiones como el chileno para otorgar beneficios que se basan estrechamente en la capacidad que tenga cada trabajador/a de cotizar mes a mes y de las decisiones que tome respecto de la gestión de sus fondos previsionales. -incluidos los problemas de agencia asociados al manejo de estos fondos por parte de administradoras privadas. Aparece, ante ello, una luz de alerta sobre cómo evaluar el desempeño del sistema y analizar sus resultados, toda vez que distinciones tradicionalmente utilizadas para dar cuenta de estos problemas como trabajo formal/informal, trabajador dependiente/independiente, decisiones racionales/irracionales, por nombrar algunas, pierden capacidad explicativa respecto de las nuevas situaciones de exclusión social que comienzan a surgir producto del funcionamiento mismo del sistema de capitalización individual.

De este modo, antes de hipotetizar sobre los problemas a los que podría estar sometido el sistema reformado y plantear nuevas modificaciones, nos parece crucial someter a crítica la base de conocimientos que ha servido de sustento para hacer análisis y proponer reformas tanto en su dimensión conceptual como metodológica. A nuestro parecer tanto los análisis, más o menos acertados sobre la situación del sistema en uno u otro momento, como las alternativas de reforma planteadas han carecido de un acercamiento comprensivo al fenómeno de la protección social en la vejez que permita a la vez, evaluar sus resultados y presentar alternativas de modificaciones adecuadas. Así, el fracaso sistemático de los sistemas de pensiones en la provisión de protección social para la vejez podría entenderse en el contexto de las limitaciones que las herramientas conceptuales y metodológicas con las que se opera desde las ciencias sociales imponen al dar-cuenta-de e intervenir-sobre los fenómenos sociales que pretenden observar. Este déficit de comprensión se traslada asimismo al nivel de la discusión política como una baja capacidad de dirección y orientación de los procesos de tomas de decisiones y reformas que terminan por generar efectos inesperados, por ejemplo, bajo la forma de posibles presiones futuras sobre el gasto fiscal en pensiones básicas y aporte solidario que tengan que venir a subsidiar la incapacidad del sistema privado de otorgar pensiones a sus afiliados/as. Así, plantea Willke, a la política comienzan a faltarle "Ios conocimientos para su orientación y los medios para la ejecución de sus programas. La sociedad pierde entonces coherencia y aparece el peligro de la desintegración: un riesgo manifiesto frente al cual la política es impotente (armamentismo, altos costos del sistema de salud, colapso del sistema de transporte, etc.)" (1995). Ello se ve particularmente acentuado en el contexto de sociedades complejas como las actuales, cruzadas por dinámicas sociales globalizadas y globalizantes, economías y mercados flexibles y expuestos a los vaivenes de los flujos de capital a nivel internacional, y el carácter eminentemente contingente y riesgoso de la toma de decisiones en todo ámbito, todo lo cual pareciera rebasar las capacidades institucionales de la sociedad para proponer nuevas formas de protección contra los problemas sociales de nuevo cuño que van apareciendo.

Surge en este escenario la necesidad de reformular el marco conceptual que se ha utilizado hasta ahora para evaluar los sistemas de pensiones y dar cuenta de sus problemas, a saber, principalmente la evolución demográfica y sus efectos sobre el financiamiento y los problemas de incentivos, ya sea en la relación aportes/beneficios o en la indefinición de los derechos sobre la propiedad de los fondos ${ }^{3}$. Sin duda estas aproximaciones dan cuenta de aspectos del problema, pero necesitan ser integradas a un esquema teórico que permita interpretar progresivamente los distintos elementos que se ponen en juego en las dinámicas de protección social suscitadas por un sistema de pensiones. Entre estas dinámicas parece fundamental poder captar dos elementos esenciales para entender su desempeño: el mercado del trabajo y la racionalidad de 
los agentes. Y esto teniendo en cuenta, a su vez, los condicionantes asociados a la inserción de dichos sistemas en un determinado contexto institucional que define su función, sus capacidades y sus límites, y los elementos internos ligados a su propio operar en tanto mecanismos de protección social.

Para llevar a cabo esta reconstrucción propondremos una serie de distinciones y conceptos que se emparientan con las corrientes institucionalistas en el intento de superar la dicotomía individuo/estructura prevaleciente en gran parte del análisis en ciencias sociales, y que se encuentran ancladas, además, en una epistemología de segundo orden en un intento por vencer al mismo tiempo los problemas que plantea la propia operación de observación. Tomaremos prestados, para ello, algunos conceptos y nociones de la teoría de sistemas (Luhmann, 1998b; 2002) que nos permitirán observar el operar de los sistemas de pensiones en tanto mecanismos de protección social y algunos enfoques sociológicos que partiendo de un individualismo metodológico logran proponer una relacionalidad entre agentes e instituciones, de modo que ni aquellos las moldean a su antojo ni estas determinan sus acciones mecánicamente (cf. Boltanski y Thévenot, 1991).

\section{PRI MER PASO: RECONSTRUIR EL ARSENAL CONCEPTUAL}

Entenderemos por instituciones aquellas cristalizaciones de sentido, espacial y temporalmente situadas, que operan probabilizando (entiéndase "haciendo más probable") una estructura de expectativas de acción en una situación social dada. Como lo plantea Luhmann: "[I]as vivencias y acciones deben apoyarse sobre una compleja red de límites selectivos, que reducen las contingencias abiertas sin eliminarlas (...). Tales estructuras hacen altamente probables expectativas variadas y acciones en la situación presente" (Luhmann, 1998c: 2). De este modo, lo improbable se convierte en posible y se hace rutinariamente anticipable. (Luhmann, 2002). Estas cristalizaciones de sentido pueden observarse concretamente en reglas, normas, convenciones, acuerdos, hábitos, costumbres, leyes, constituciones, etc., lo que da cuenta de distintos niveles de profundidad institucional y grados de formalización en que estas pueden inscribirse. Las instituciones permiten enlazar expectativas de acción al operar autónomo de sistemas psíquicos y sistemas sociales reduciendo la contingencia y la incertidumbre al promover interacciones sobre un horizonte de certezas en dos planos: en el de la coordinación social, generan lo que Giddens (1998) denomina una "seguridad ontológica" que permite actuar de manera individual sin tener que poner en cuestión la construcción del orden en cada situación de interacción, ${ }^{4}$ mientras que en el plano de la coordinación sistémica permite limitar las opciones de la diferenciación al trazar vías de dependencia institucional (path dependence) (North, 2006). A partir de los trabajos de Polanyi (1957; 2003) surge, por otro lado, una forma de entender el operar de las instituciones en virtud de su carácter incrustado (embedded) en redes de relaciones sociales, donde estas serían puestas a prueba en un movimiento constante y recursivo de estructuración de expectativas de acción y cambio institucional.

Siguiendo a Luhmann (1998a), la sedimentación de instituciones puede entenderse en el contexto de la operación básica a través de la cual discurre la evolución social como proceso de diferenciación: la distinción entre sistema y entorno. A nuestro juicio sociedades como la chilena se encuentran tensionadas por las presiones que generan dos de estas formas de diferenciación social: la estratificación, por una parte, que supone una distribución inequitativa de las posibilidades de comunicación arraigadas en subsistemas desiguales que alinean la asimetría sistema/entorno con la de igualdad/desigualdad (Luhmann 1998a: 4), generando una distribución desigual de los 
recursos disponibles en la sociedad como el poder y la riqueza -distribución desigual de las posibilidades de comunicación-, y la diferenciación funcional que dispone los procesos de comunicación en torno a funciones que se organizan en subsistemas especializados que ganan cada vez mayor autonomía, generando sociedades policéntricas en que cada subsistema reclama la superioridad de sus propios códigos.

En este contexto resulta interesante rescatar dos elementos centrales que aporta la teoría de sistemas tal como la presenta Luhmann (1998a). Por un lado, la distinción entre estructura y semántica que nos permite diferenciar entre forma y contenido, esto es, entre las instituciones propiamente tales o la estructura de un sistema y los relatos que se hacen de ellas, del proceso de su formación y de sus funciones. Por otro lado, la distinción inclusión/exclusión que, a diferencia del concepto de integración social tradicionalmente utilizado en sociología para dar cuenta del equilibrio de cohesión que se genera en torno a una norma, permite comprender como parte de una misma dinámica social tanto los elementos centrífugos como centrípetos, es decir, la exclusión social como la otra cara de la inclusión misma. ${ }^{5}$ De este modo, una determinada semántica opera guiando la dinámica de diferenciación social y la sedimentación de instituciones, proveyendo a la vez una justificación a las operaciones de inclusión y exclusión que llevan a cabo los distintos sistemas así surgidos.

\section{Los sistemas de pensiones como mecanismos de protección social}

Los sistemas de pensiones deben comprenderse dentro del conjunto de instituciones que conforman lo que denominaremos genéricamente mecanismos de protección social. ${ }^{6}$ En su forma moderna, los mecanismos de protección social pasan a convertirse en un eje fundamental de la dinámica societal al actuar como proxys de la inclusión social. Esto se hace posible en gran medida gracias a que hacia fines del siglo XIX y aún durante gran parte del siglo $X X$ las sociedades modernas continúan siendo ampliamente dominadas por formas de diferenciación estratificadas. Esta condición significa, por un lado, que el sistema político actúa como pivot o centro de esta dinámica, lo que le permite dirigir las formas de orientación de las comunicaciones al interior de la sociedad, y en segundo lugar, que la exclusión del sistema económico genera en la mayoría de los casos una cadena de exclusiones contiguas. De este modo, se entiende que con una operación de re-inclusión políticamente regulada de las personas en el sistema económico, a través de, por ejemplo, de un suplemento del salario, estas puedan insertarse adecuadamente en otros subsistemas. Este constituye precisamente el principio fundante de los mecanismos de seguro social, precursores de los sistemas de seguridad social contemporáneos.

Podríamos decir que la forma específica en que los mecanismos de protección social hacen posible la inclusión es a través de una operación de re-inclusión, esto es, un incluir-desde-la-exclusión. Según Luhmann (1998a), la operación de inclusión de un sistema define a partir de determinados códigos aquellos seres humanos pertinentes de ser incluidos en las direcciones comunicativas. Es decir, se los las entiende como sujetos a expectativas y en tanto que tales, re-incluibles en la dinámica de las comunicaciones de un sistema funcional a partir de determinadas reglas de acceso. De este modo, los mecanismos de protección social son instituciones que operan organizando una estructura de expectativas de re-inclusión en torno a una forma persona (ver diagrama 1). De la diferencia temporal en la estructura de expectativas de protección social, por otro lado, surge la distinción entre mecanismos de aseguramiento, que anticipan estados de exclusión futura como puede ser un sistema 
de pensiones, y mecanismos de compensación, que actúan sobre exclusiones ya realizadas como pueden ser las políticas asistenciales.

Diagrama 1: Operación de re-inclusión de un sistema de protección social

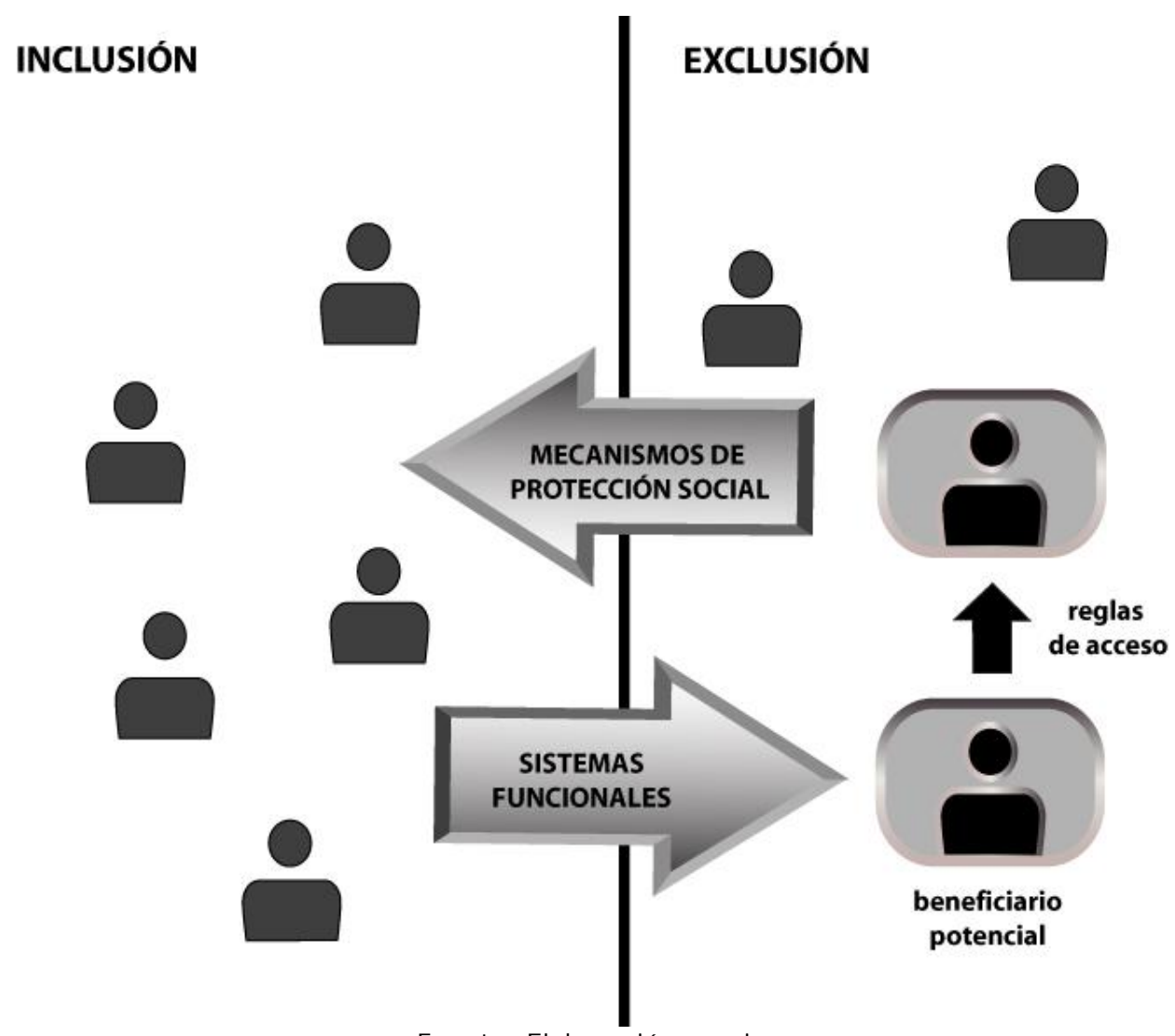

Fuente: Elaboración propia

Por otro lado, si a esta dinámica de protección social aplicamos la re-entry de la forma inclusión/exclusión en ambos lados de la distinción, obtenemos un mapa de zonas de protección que permite complejizar el esquema anterior al incorporar a las zonas de inclusión y exclusión, otras dos que hemos denominado zonas de vulnerabilidad (ver diagrama 2). La primera, de exclusión en la inclusión, que denominaremos inclusión espuria refiere a aquellas situaciones en que la operación de re-inclusión queda a medio camino, no pudiendo identificarse en el lado de exclusión exitosa propiamente tal. Situaciones de este tipo podría identificarse, por ejemplo, cuando los beneficiarios de ciertas políticas o programas son objeto de semantizaciones que llevan a su estigmatización ${ }^{7}$, o producto de que las prestaciones otorgadas no son suficientes para insertarse de manera efectiva en otros subsistemas. Del otro lado, tenemos el casillero de inclusión en la exclusión, que refiere a situaciones de exclusión donde básicamente operan formas de protección informales que permiten superar algunos riesgos. Ello pudiera identificarse, por ejemplo, en prácticas de tipo comunitarias como la movilización de capital social u otros activos de ese orden, la reproducción de las cuales produce circuitos alternativos -en los márgenes- a los oficialmente establecidos. 
Diagrama 2: Zonas de protección social con re-entry de la forma inclusión/ exclusión

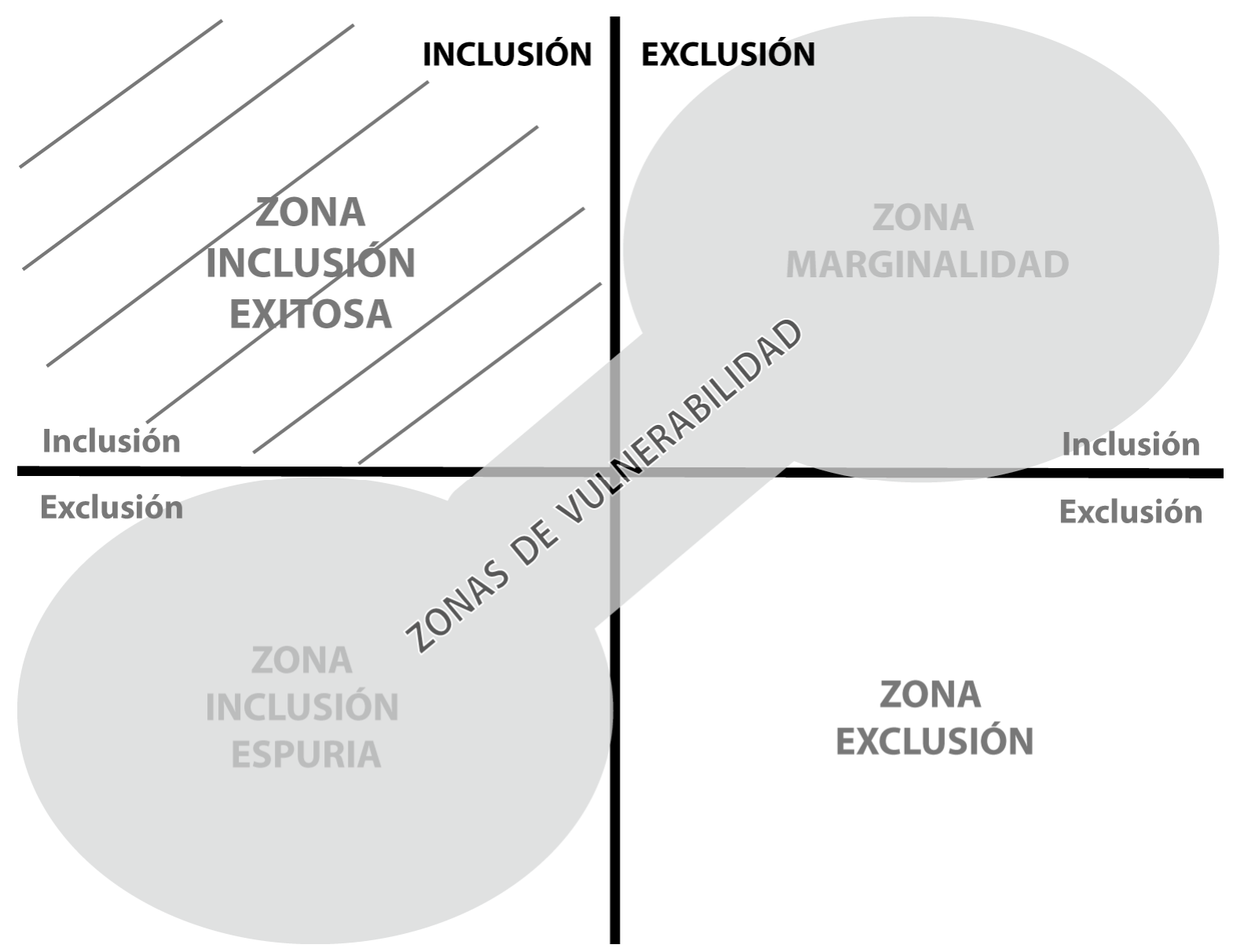

Fuente: Elaboración propia

1.2. Mecanismos de protección social y el nivel individual

Las estructuras de expectativas de inclusión de personas que son provistas por una determinada semántica, se solidifican en dispositivos institucionales específicos como es el caso de un sistema de pensiones. Estos coordinan probabilidades de re-inclusión a partir de las prestaciones ofrecidas por una serie de subsistemas y medios que los hacen funcionar (la economía y el mercado, la familia, la política y el estado; el medio físico-orgánico, la economía, la cultura, etc.). En este procedimiento de coordinación no debe dejar de tomarse en cuenta el enlace que estos mecanismos deben hacer de las expectativas de inclusión con el actuar de las propias personas en dicha red de límites selectivos. En efecto, en tanto sistemas psíquicos las personas llevan a cabo un particular procesamiento de las ofertas comunicativas que suponen las expectativas de inclusión, lo que pone como tema necesario el abordar las formas de procesamiento de información y de toma de decisiones por parte de los propios agentes sociales.

Para superar las concepciones de una racionalidad sustantiva o maximizadora que impone una carga informativa y capacidad de codificación imposibles de llevar a cabo por un agente socialmente situado en situaciones de la vida cotidiana, Simon (1982) 
plantea utilizar la idea de una racionalidad limitada. Adoptar un supuesto de racionalidad limitada implica asumir que los agentes sondean un número más bien pequeño de opciones estableciendo "umbrales de satisfacción" que son ajustados de manera dinámica a la realidad sobre la base de la información disponible y las posibilidades que ofrece el contexto. El carácter procedimental de esta racionalidad limitada se expresa en la dependencia de las decisiones respecto del proceso que las genera, esto es, la acumulación de información de varios tipos y fuentes, y la formación de creencias a partir del procesamiento de esta información y su codificación en función de distintas orientaciones posibles. Todo lo cual lleva a obtener un curso de acción entendido ya no como racional sino como razonable (Simon, 1982). ${ }^{8}$ Desde este punto de vista, el problema de la racionalidad que ha sido tematizado cuando se habla de los incentivos que incorporan los mecanismos de protección social cambia drásticamente a la pregunta por las buenas razones o la razonabilidad de las decisiones en función de las instituciones - reglas, normas, costumbres- que les sirven de referencia.

Las expectativas de inclusión social que ofrecen los mecanismos de protección social representan precisamente un conjunto de reglas disponibles para que los agentes guíen sus prácticas en materia de previsión social. Sin embargo, dado que en tanto sistemas autopoiéticos los agentes siguen sus propias dinámicas sin que la lógica que subyace a estos procesamientos se encuentre disponible a la comprensión por parte de otro sistema, mientras no exista una forma de asegurar la eficacia en la coordinación que dichas reglas pretenden producir, el procesamiento individual de las reglas y normas generará tantas interpretaciones y cursos de acción como conciencias interesadas existan, traduciéndose ello en prácticas divergentes que no tendrán el éxito esperado en materia de inclusión social. Para desarrollar este punto es que recurrimos a los planteamientos de Boltanski y Thévenot (1991) sobre la capacidad de la normatividad inscripta en las instituciones de sustentar modelos eficaces de coordinación social. Bajo este enfoque, las expectativas recíprocas son coordinadas por principios normativos que sustentan modelos de ordenamientos sociales típicos que pueden ser identificados por los agentes en virtud de los elementos sociales y objetuales involucrados en cada situación. La norma, en este contexto, tiene la virtud de generar ordenamientos coherentes que permiten ajustar las interpretaciones mutuas, no porque se encuentre internalizada por los agentes, sino por sus rendimientos en cuanto a ofrecer pautas de acción inscriptas en modelos de orden social considerados legítimos. Sin la necesidad de internalizar dichas pautas, las personas se encontrarían dotadas de una competencia que en una situación cotidiana les permitiría identificar estos ordenamientos a partir del lugar que ocupan las personas y los objetos en la interacción, generándose una red de expectativas recíprocas altamente probables de ser seguidas. Para ello sería crucial el papel de las instituciones y la forma en que dichos órdenes se inscriben en ellas. Una forma similar de abordar el problema de la coordinación es la que plantean autores como Renate Maynz (2000) a partir del concepto de governance. Este hace referencia a modalidades de coordinación entendidas como "formas primarias de construcción del orden social" (36), esto es, formas de gobierno de un conjunto de relaciones sociales que se basan en un determinado principio de orientación de las mismas.

Podemos suponer, siguiendo esto, que la semántica a partir de la cual se institucionalizan los mecanismos de protección social lleva implícito un modelo de acción legítimo que es formalizado en determinados procedimientos o programas decisionales. Estos programas ofrecen a los agentes cursos de acción bajo la forma de "opciones" o "elecciones" individuales dotadas de sentido. Las acciones posibles en materia de protección social, incrustadas en una red de relaciones entre agentes 
sociales y sistemas, pueden limitarse y hacerse probables precisamente a través de su inscripción en este tipo de modelos. Los mecanismos de protección social basarían así su efectividad para generar inclusión social en función de su inscripción en una determinada semántica de la inclusión que ofrece referencias a modelos legítimos de relaciones entre los agentes y los objetos involucrados en dichas relaciones, incluyendo además programas decisionales bajo la forma de elecciones posibles dotadas de sentido.

\subsection{El lugar de los mecanismos de protección social en las sociedades modernas}

En la institucionalización de los mecanismos de seguridad social y de las expectativas de inclusión que estos contienen, juega un rol de suma importancia el sistema jurídico que permite entender la estructura de probabilidades así dispuesta bajo la forma de una estructura de oportunidades. El concepto de estructura de oportunidades debiera entenderse en este contexto como un conjunto de reglas de acceso a probabilidades de re-inclusión que se encuentran definidas y garantizadas jurídicamente. Ello, a su vez, permite reconocer los límites institucionales de estas expectativas, anclados en las posibilidades que tienen los propios sistemas funcionales y otras instituciones de ofrecer prestaciones de protección social. Las posibilidades de re-inclusión se ven condicionadas así por los elementos organizativos propios de cada sistema - en términos de su eficacia para guiar acciones hacia objetivos colectivos-, como también por el conjunto de relaciones entre sistemas que constituye un entorno societal común.

Se hace necesario, a este punto, distinguir las semánticas que dan forma a los entornos (interno y externo) en los que se insertan los mecanismos de protección social. Ello permite, por un lado, comprender el lugar que estos ocupan en una sociedad dada -incluyendo sus límites institucionales-, y por otro, sus formas organizativas propias, en estrecha relación - de dependencia- con la matriz institucional que da forma a una sociedad. Diremos de este modo que los mecanismos de protección social se encuentran incrustados (embedded) en un conjunto de relaciones sociales orientadas por dos megarreferencias que actúan como marcos para la diferenciación social/constitución de instituciones y la acción de los agentes sociales: una semántica que guía la organización de una sociedad histórica en términos amplios, esto es, que gobierna la diferenciación social y la cristalización de instituciones por largos espectros de espacio y de tiempo, que llamaremos norma de regulación social; y otra semántica que denominaremos norma del bienestar, que define las formas de la inclusión/exclusión en el ámbito de la protección social y las instituciones implicadas en ello, y que actúa como justificación y referencia para las prácticas de agentes sociales en esa materia. En las sociedades contemporáneas, como hemos visto, esta última condición tiende a institucionalizarse bajo la forma de una estructura de oportunidades, es decir, definirse y garantizarse jurídicamente.

Dado que nuestro interés está en el captar la forma de operar de un sistema de pensiones -en tanto mecanismo de protección social- como base para poder emprender un análisis de su desempeño que sirva para plantear alternativas de reforma, desarrollaremos más ampliamente el concepto de norma del bienestar.

Una norma del bienestar debe entenderse como un relato normativo que opera en la constitución de mecanismos de protección social y en su institucionalización en estructuras de oportunidades, es decir, establece la forma de operar específica de un mecanismo de protección social en un lugar y tiempo. En tanto semántica de la inclusión, una norma del bienestar opera definiendo las personas incluibles (los 
beneficiarios de la protección social) y otorgando una forma específica a los mecanismos de protección social. Cada norma del bienestar define el tipo de persona adecuado para la re-inclusión, determina reglas de acceso a las prestaciones de protección social y se identifica por incorporar una forma típica de coordinar las prestaciones funcionales a disposición: a partir de relaciones de proximidad social (al interior de la familia), de manera pública y centralizada, basada en mandatos emanados por una autoridad (como un sistema organizado estatalmente), de forma descentralizada y privada (a partir de proveedores privados dispuestos en un mercado). La cristalización de una norma del bienestar en instituciones específicas encargadas de la coordinación de prestaciones de protección social necesita, a su vez, de su inscripción en programas decisionales que permitan incorporar modelos legítimos de agentes y sus acciones de manera de probabilizar (coordinar de manera efectiva) sus resultados en materia de protección social.

Además de servir de referencia sistémica en la constitución de estructuras relacionadas con la protección social, una norma del bienestar opera también como un principio normativo que permite justificar las formas que asume la inclusión social en una sociedad determinada y a su vez, incorporar las situaciones de exclusión social como parte de un mismo relato coherente. La norma del bienestar define, así, lo que en una sociedad se consideran los niveles de bienestar adecuados o aceptables - lo mismo respecto de las situaciones de exclusión- y ofrece una explicación del por qué un determinado estado de distribución del bienestar es justo. Podemos reconocer por tanto un operar de una norma del bienestar en dos niveles: a nivel sistémico se ajusta a la norma de regulación que gobierna la organización de una sociedad histórica y tiene una función preponderante en su legitimación, particularmente del sistema político. A nivel de las relaciones sociales, la norma del bienestar estructura modelos de acción legítimos que son utilizados por los agentes para desarrollar sus prácticas en materia de protección social.

Una norma del bienestar permite así integrar coherentemente la dinámica de protección social en una sociedad: definiendo y dando contenido a una particular combinación de prestaciones funcionales (familia-estado-mercado) y dispositivos institucionales (prácticas de cuidado, asistencia social, seguros sociales, etc.) y justificando las operaciones de inclusión y exclusión al apelar a principios como el utilitarismo, el liberalismo, el marxismo, la ciudadanía marshalliana, el bienestar, la calidad de vida, etc. y variantes específicas que pueden observarse, por ejemplo, en las teorías de la justicia.

Una norma del bienestar posee además una autorreferencialidad que le permite establecer medidas del éxito o del "rendimiento social" de las operaciones de reinclusión que sustenta. Para diferenciarlas, a estas medidas del éxito, les hemos denominado normas del desempeño. La norma del desempeño asociada a una norma del bienestar permite a esta última superar las situaciones críticas en que se pone en cuestión la justicia de los estados de inclusión producidos. Esto puede suceder por ejemplo, debido a la interferencia de códigos ajenos, ya sea que provengan de otros subsistemas o de otras normas del bienestar. La norma del desempeño debe entenderse, en este contexto, como la forma específica de justificación que posee una norma del bienestar. 
Nuevas aproximaciones para el análisis de sistemas de protección social: La noción de desempeño

\section{Los sistemas de pensiones como mecanismos de protección social y el caso chileno}

Los sistemas de pensiones constituyen un mecanismo de protección social que opera la re-inclusión de personas teniendo como referencia primordial su exclusión del mercado del trabajo. Esta exclusión se genera como el otro lado de la inclusión por el funcionamiento de una regla de acceso que define estándares de productividad y capacidades típicas, rangos de edades, etc. ${ }^{9}$ La exclusión del mercado del trabajo se traduce típicamente en una situación de vulnerabilidad por falta o limitación de un ingreso, de modo que la re-inclusión se produce a partir de dispositivos que permiten otorgar beneficios que complementan/sustituyen el salario, y que incluyen típicamente un tipo de compensación económica al momento de cumplir una cierta edad de salida del mercado del trabajo (pensiones de vejez), otra para quienes se encuentran física y mentalmente incapacitados para trabajar (pensiones de invalidez), o se encuentran apartados de la posibilidad de inclusión autónoma a través del mercado del trabajo, generalmente por edad o sexo (pensiones de sobrevivencia en caso de muerte del jefe del hogar). Un sistema de pensiones constituye un dispositivo institucional que establece reglas específicas para resolver una serie de cuestiones referentes a la pérdida de ingresos producto de la exclusión del mercado del trabajo: quiénes pueden ser beneficiarios, cómo se determina el nivel de los beneficios, cuál es el grado de solidaridad del sistema, cuál es el nivel de consumo a reemplazar, cómo y quién financia las prestaciones, cómo se evalúa su desempeño, etc. Los dispositivos incluidos en un sistema de pensiones incorporan típicamente tanto elementos de aseguramiento (beneficios asociados a contribuciones a un seguro durante la vida laboral) como de compensación (beneficios otorgados por una evaluación ex-post de las condiciones de vida, generalmente sin necesidad de contribución). Todo ello definido y garantizado legalmente bajo la forma de una estructura de oportunidades.

En tanto mecanismos de protección social, los sistemas de pensiones coordinan expectativas de re-inclusión principalmente a partir de las prestaciones que provee la familia, el mercado y el estado. A su vez, los sistemas de pensiones probabilizan las expectativas de inclusión así presentadas ajustándose a una norma del bienestar, lo que permite incorporar hipótesis respecto de cómo actuarán los agentes ante las ofertas institucionalizadas de protección social (welfare input), aumentando teóricamente- la probabilidad de una efectiva coordinación de las respuestas individuales a las ofertas de inclusión.

El sistema pensiones chileno coordina las probabilidades de inclusión social en función de la norma del bienestar individualista/liberal. Esta norma se orienta típicamente a la protección de trabajadores en su condición de personas individuales, enfatizando la capacidad de los mismos de gestionar su propio bienestar. El mercado asume una posición dominante, tanto como proveedor de prestaciones de protección social y como modo de coordinación de las prestaciones de los distintos sistemas involucrados. Es decir, no sólo las pensiones se definen en un mercado de administradoras privadas, sino que además se asumen supuestos propiamente mercantiles respecto de la coordinación de las respuestas individuales (asociadas a elementos como una racionalidad medios/fines), las prestaciones ofrecidas por el estado (subsidios focalizados de carácter asistencial), etc. A ello se añade una norma del desempeño basada en el principio de la eficiencia, de lo que se desprende una normatividad que premia las conductas individuales maximizadoras en tanto beneficiosas para el conjunto de la sociedad. Permite, así, justificar una distribución del bienestar en virtud del emprendimiento o iniciativa individual, entendiendo que mientras la mayor utilidad 
de algunos no disminuya la de otros, el resultado en términos de bienestar es socialmente justo (óptimo de Pareto).

La forma típica que asume la protección social en la vejez bajo la norma individualista/liberal es en los sistemas de capitalización individual. La sustitución del antiguo sistema de reparto por el de ahorro individual en el caso chileno y en del resto de los países que siguieron su modelo, debe entenderse en el contexto del cambio institucional y el paso desde una norma de regulación social emparentada con el fordismo a otra de tipo flexible, caracterizada por una intensificación de la competencia especialmente a nivel internacional, el dominio del sector productivo terciario, la financiarización de la economía y la pérdida de importancia del Estado a favor del mercado como principal mecanismo de coordinación social (Boyer, 2007; Lechner, 1997).

El principio que guía los sistemas de capitalización individual es que los beneficios no están definidos a priori sino que dependen estrictamente de las contribuciones hechas en cuentas individuales, llamados por ello "de capitalización de contribuciones definidas" en oposición a los sistemas de reparto de "beneficios definidos" que aseguraban pisos de bienestar con cierta independencia de los aportes individuales. Se utiliza además el término "capitalización" porque las contribuciones depositadas en cuentas individuales son invertidas en instrumentos financieros de los que obtienen una rentabilidad (son capitalizadas). De manera que el monto de las pensiones depende únicamente de los esfuerzos contributivos individuales y la capacidad de los beneficiarios/as de elegir correctamente dónde colocar sus fondos y a quién confiarlos. El desempeño de estos sistemas se evalúa así a partir de la eficiencia de las decisiones que toma cada individuo respecto de su previsión. De ahí que las reformas propuestas para mejorar el desempeño de los sistemas de capitalización individual se centren en el establecimiento de incentivos para la toma de decisiones (véase Berstein y otros, 2005).

Este nivel -el principal- de ahorro individual es complementado en Chile por un segundo nivel compensatorio de tipo no contributivo constituido por lo que antiguamente se denominaba PASIS (Pensión asistenciales) y que en el contexto de la reforma actual ha pasado a denominarse PBS (Pensión Básica Solidaria). Si bien ambas son distintas en cuanto a los montos involucrados y la población beneficiaria, las dos se asientan plenamente en la función residual asignada por la norma del bienestar individualista/liberal a las prestaciones organizadas a nivel del estado, es decir, se entienden como necesarias únicamente en el marco de suplir las "fallas del mercado" y en el establecimiento de niveles de beneficios relativamente bajos de modo de no generar "incentivos adversos" a la no cotización.

A continuación presentamos la elaboración de un modelo de análisis que hemos denominado análisis de desempeño institucional para el sistema de pensiones chileno. En virtud de la primacía del componente "ahorro individual" el modelo se centrará en el desempeño de este nivel. Ello más que una limitación constituye una ventaja pues permite evaluar el desempeño de un sistema de pensiones de ahorro individual en el caso paradigmático que ha constituido el sistema chileno. Al mismo tiempo, los resultados obtenidos de su aplicación permitirían obtener conclusiones relevantes respecto de las hipótesis sobre las que se asientan estos modelos referentes, por ejemplo, al funcionamiento de los mercados del trabajo y de la toma de decisiones por parte de los agentes. Esto último resulta pertinente no sólo en el contexto de las decisiones individuales respecto del tipo de fondo y administradora donde se ponen los recursos, sino también respecto de las propias decisiones de inversión de las 
administradoras. ${ }^{10}$ De la misma forma, permitirían sacar cuentas sobre la magnitud de las "fallas del mercado", y en ese sentido, hacer la evaluación de los costos en que debiera incurrir el Estado para cubrir dichas fallas a través de pensiones básicas.

\section{SEGUNDO PASO: DESEMPEÑO I NSTI TUCI ONAL, UN MODELO DE ANÁLI SIS}

El desempeño institucional de mecanismos de protección social consiste en una descripción de sus resultados en términos de la coordinación de las prestaciones de protección social de sistemas específicos y de las respuestas individuales a dichas ofertas. El resultado puede entenderse como un cruce entre las expectativas de inclusión semánticamente ofrecidas y las posibilidades estructuralmente determinadas, y su descripción en términos de inclusión/exclusión (ver diagrama 3). La ventaja de utilizar un marco de análisis como este reside en que la evaluación del desempeño de un mecanismo de protección social se realiza en función de su propia forma de operar, esto es, sin incorporar elementos normativos adicionales a los incluidos en la propia operación de observación o análisis. Esto parece relevante en la medida en que se supera la mera confrontación de normatividades distintas por ejemplo eficiencia v/s equidad, que parecen adecuadas para una discusión semántica respecto del diseño de políticas, pero no así respecto de la presentación de resultados bajo los códigos propios del sistema científico.

Las expectativas de inclusión se encuentran determinadas por la norma del bienestar que organiza los mecanismos de protección social e inscritas en un orden jurídico que establece marcos generales y específicos de garantías y derechos. El acceso efectivo a dicha red de expectativas se regula a través de una regla que establece condiciones mediante las cuales se selecciona las personas re-incluibles (beneficiarios). De este modo, el desempeño institucional puede medirse a partir de las reglas de acceso y su anclaje jurídico, que determinan probabilidades de inclusión legítimamente esperables y llevan implícitas hipótesis sobre sus determinantes institucionales. Sostenemos que tal observación es posible identificando los pasos de su operar institucionalmente.

Siguiendo lo anterior y nuestra discusión en la sección II, para hacer una evaluación de desempeño institucional se requiere develar el operar de los mecanismos de protección social en tres momentos:

1. En el lugar que ocupan en un determinado ambiente sistémico y las prestaciones funcionales de otros sistemas que son posibles de ser utilizadas (determinado por el operar específico de una norma de regulación social).

2. En la forma que adoptan los dispositivos institucionales concretos en la coordinación de prestaciones funcionales y agentes (determinada por el operar de una norma del bienestar). Y dentro de ello, los particulares modelos de coordinación de las acciones de agentes que incorporan.

3. En las formas de la justificación que ajustan los resultados de dicha coordinación (que se establece a partir de una norma del desempeño).

El concepto de estructura de oportunidades es clave para elaborar un modelo de análisis bajo las premisas del "análisis de desempeño institucional". Esto gracias a que permite identificar como funciona un sistema de pensiones pues define, a través de una regla de acceso, los beneficios ofrecidos y los requisitos para acceder a ellos, donde: 
- Los beneficios ofrecidos representan las expectativas de inclusión que son justificadas por una norma del desempeño y por tanto, sirven como indicador de los niveles de bienestar esperados en contraste con los realmente alcanzados, es decir, actúan como indicador del desempeño del sistema.

- Los requisitos para acceder a ellos llevan implícitas hipótesis respecto del funcionamiento de los condicionantes estructurales, que podemos identificar en:

- Regla de acceso 1: Cotización. Supone la capacidad de las personas de contribuir mes a mes al fondo individual. Esto conlleva hipótesis sobre el funcionamiento del mercado del trabajo relacionados a los niveles de empleo, salarios, participación femenina, etc. Esta regla de acceso incorpora las determinaciones estructurales que el mercado del trabajo impone al desempeño del sistema de pensiones, es decir, se relaciona con la norma de regulación social.

- Regla de acceso 2: Racionalidad. Supone la capacidad de las personas de tomar decisiones racionales en contextos de alta complejidad. Esto conlleva hipótesis no sólo sobre la completitud de la información disponible, sino que apela directamente a la posesión de capacidades por parte de los agentes y una forma particular de procesar información y gestionar la incertidumbre. Esta regla de acceso incorpora las determinaciones que las decisiones individuales imponen al desempeño del sistema de pensiones y los rendimientos de los mecanismos de coordinación de las mismas, que remiten a una norma del bienestar. 
Diagrama 3: Desempeño institucional sistema de pensiones de capitalización individual

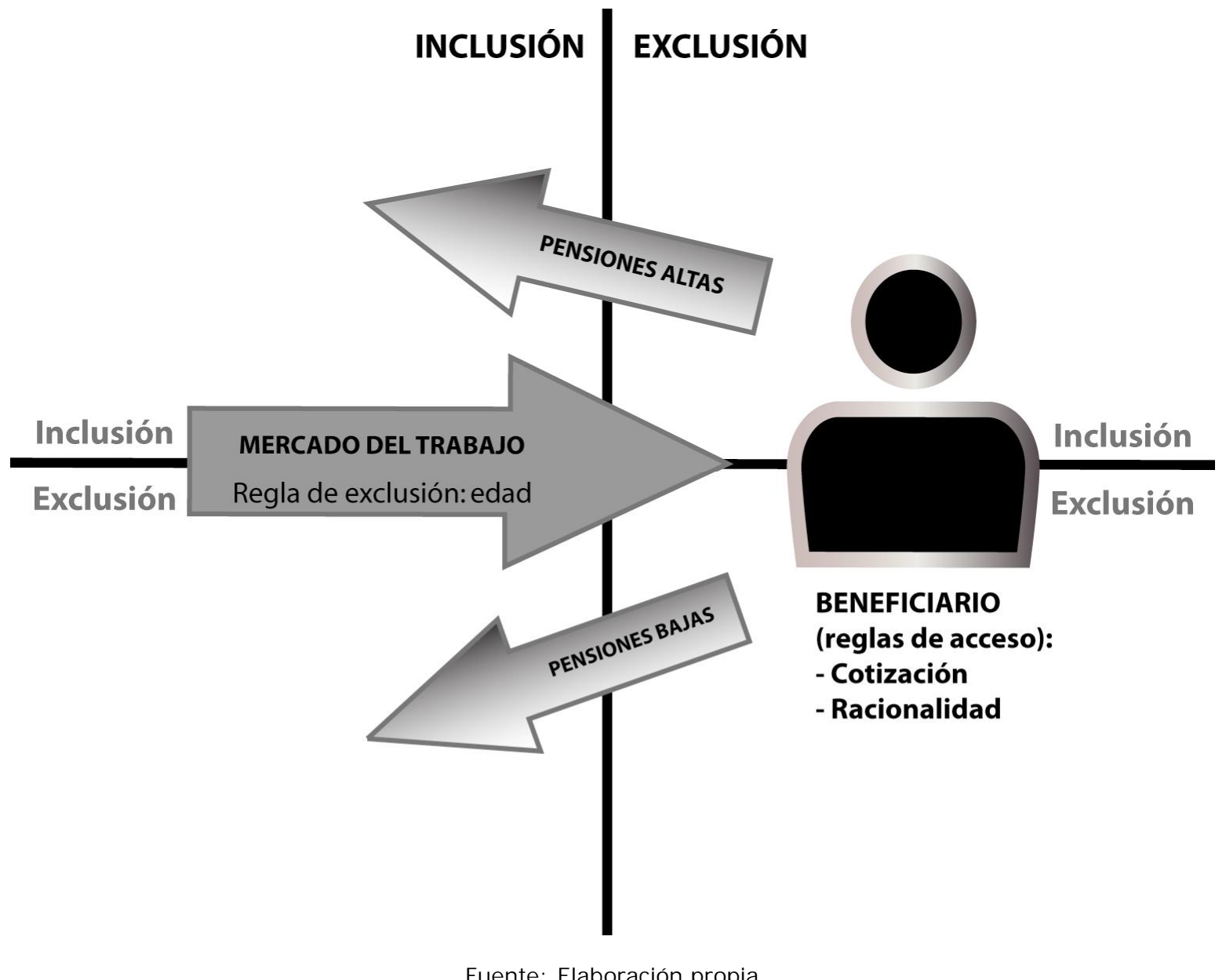

A continuación se describirá brevemente los fundamentos a partir de los cuales se operacionalizaron los tres elementos señalados, los indicadores del desempeño y las dos reglas de acceso.

\subsection{Indicador del desempeño: calidad de la cobertura}

Al observar la justificación con que operan distintas normas del desempeño en el caso de los sistemas de pensiones, incluida la de eficiencia, hemos encontrando que la evaluación se apoya en el comportamiento de dos indicadores: el no de personas protegidas (que llamamos cobertura poblacional) y el monto de los beneficios (que llamamos calidad de la cobertura). ${ }^{11}$

En el caso de los sistemas de reparto, debido a que los beneficios se encuentran definidos por la fórmula misma de cálculo, la justificación se ha apoyado típicamente en el indicador de cobertura poblacional que permite evaluar el desempeño a nivel sistémico. El indicador de cobertura poblacional comienza a hacerse problemático recién con la introducción de sistemas de ahorro individual en que los beneficios dejan de estar definidos. Esto introduce una dificultad en la evaluación del desempeño en los países en desarrollo: si bien sigue siendo cierto que quienes trabajan en el sector 
informal se encuentran excluidos por su falta de acceso al sistema, tampoco los trabajadores del sector formal tienen asegurada su modalidad de inclusión social pues los beneficios son muy bajos, lo que genera amplias zonas de inclusión espuria. De este modo, el concepto de cobertura poblacional comienza a dejar de ser eficaz para evaluar el desempeño del sistema. Este es precisamente el caso puesto en evidencia por el sistema de pensiones chileno que presenta altos niveles de cobertura pero bajos beneficios medidos como tasa de reemplazo del último salario (CENDA-INP, 2005). Tal como muestran las estadísticas de afiliación a las AFP, la mayoría de los trabajadores se encuentran afiliados como trabajadores dependientes y sólo un pequeño porcentaje como independientes (CENDA-INP, 2005). Esto indica que en el nuevo modelo productivo los trabajadores migran constantemente desde ocupaciones asalariadas a ocupaciones no asalariadas y viceversa, lo cual hace ineficaz la distinción formal/informal para evaluar el desempeño del nuevo sistema de pensiones. ${ }^{12}$

Tal como apunta Berstein y otros (2005) con los sistemas de capitalización individual la evaluación del desempeño debe centrarse en el monto de los beneficios alcanzados (indicador de calidad de la cobertura) y no en la cantidad de gente asegurada. Este nos permite, efectivamente, dar explicaciones respecto del rendimiento diferenciado de las decisiones individuales en el desempeño del sistema de pensiones.

\subsection{Regla de acceso 1: cotización}

Si tan sólo seguimos las descripciones típicas de Marx, Polanyi (2003), Castel (2006) y muchos otros, debemos entender que las estructuras de oportunidades en las sociedades capitalistas establecen al trabajo como el principal activo para promover el bienestar de los individuos. El contrato entre capital y trabajo que implica el intercambio de fuerza de trabajo por un pago monetario permite no sólo la inclusión a través del salario mismo, sino que además propicia la re-inclusión toda vez que un sistema de pensiones como el de capitalizacion individual condiciona los beneficios a los aportes realizados a lo largo de la vida. El desempeño en el mercado del trabajo es así condicionante fundamental en tanto los beneficios se basan en los descuentos sobre el salario que mes a mes un trabajador aporta al sistema. El desempeño del mercado del trabajo determina en gran medida la capacidad contributiva de un individuo, y en virtud de ello, el monto de su pensión.

El desempeño del mercado del trabajo puede analizarse a partir de su propia regla de acceso que genera inclusiones y exclusiones. Esta se establece en un contrato de trabajo donde se definen precisamente las modalidades de inclusión de las personas a partir de reglas respecto de:

- Puestos de trabajo y su jerarquía

- Competencias y/o calificaciones requeridas para cada puesto

- Tiempo y lugar de trabajo

- Organización del proceso productivo

- Retribución o salario

- Forma de evaluación

La regla de acceso que hemos identificado en la cotización actúa básicamente con la hipótesis de que el mercado del trabajo presentará un comportamiento relativamente estable. Así lo expresa de manera enfática Bertranou: "El segundo requisito para los programas contributivos consiste en la regularidad o estabilidad en el empleo, es decir, no sólo hace falta una relación laboral formal, en general asalariada, sino que también se requiere que la tasa de rotación en el empleo no sea demasiada alta." (2004: 17).

Revista Mad. $N^{\circ}$ 20, Mayo de 2009. Departamento de Antropología. Universidad de Chile 
Como la pensión futura depende de las contribuciones al seguro, contar con un empleo estable y remuneraciones altas es indispensable para lograr altas tasas de reemplazo.

Boyer (2006) propone adicionalmente la existencia de una segmentación de estas reglas de acceso según sectores productivos o incluso al interior mismo de una empresa en el caso de empresas grandes. Como cada segmento establece reglas diferenciadas para acceder a los estados de inclusión y exclusión, el desempeño del mercado del trabajo no podría aprehenderse de manera agregada, sino sólo en función de lo que sucede en términos de inclusión y exclusión al interior de cada segmento. Las reglas de acceso asociadas a cada segmento interno definen una entrada diferenciada a las posibilidades de inclusión en el mercado del trabajo, generando al mismo tiempo capacidades de contribución al sistema de pensiones diferenciadas. Podría hablarse a partir de esto de segmentos de personas re-incluibles para los mecanismos de protección social. De este modo, al evaluar con la misma vara personas con características distintas, los sistemas de pensiones reproducen los segmentos del mercado del trabajo en las expectativas de inclusión que ofrecen. De aquí que pueda esperarse un desempeño segmentado del sistema de pensiones.

\subsection{Regla de acceso 2: racionalidad}

En el ámbito de las respuestas de los agentes a las ofertas de protección social debemos estar en condiciones de operacionalizar el funcionamiento de un sistema de pensiones en dos ámbitos: i) el de cómo utilizan los agentes los parámetros que este ofrece para tomar decisiones al momento de obtener una pensión, y ii) el de qué modelo de acción y de agente típico incorpora un sistema de pensiones dado para resolver la coordinación de las acciones individuales.

Tomando como referencia el esquema de tres elementos que a juicio de Kaztman y Filgueira (1999) participan en la toma de decisiones de los agentes cuando intentan acceder a determinadas estructuras de oportunidades para mantener o mejorar sus niveles de bienestar, intentaremos imaginar tres niveles sucesivos de construcción de las respuestas individuales a las probabilidades de inclusión ofrecidas por los mecanismos de protección social:

- Recurso: existe un elemento externo al individuo que le permite adoptar una postura de observador y mapear su entorno, lo que hace posible el procesamiento de las probabilidades de inclusión institucionalmente determinadas. A los recursos relevantes en cada caso les denominaremos genéricamente "información". El primer nivel necesario para generar una respuesta individual corresponde a la posesión de información, donde la amenaza concomitante resulta de la falta de información, ya sea entendida como "percepción de..." o como un estado objetivo del entorno.

- Capacidad: existe asimismo una característica atribuible al propio individuo que dice relación con su facultad para procesar las probabilidades de inclusión ofrecidas por un mecanismo de protección social. Este es un supuesto contenido en la posibilidad misma de la interacción y se refiere a las competencias de los individuos entendidas como códigos (habilidades cognitivas) que permiten descifrar la información proveniente del entorno. La amenaza en este nivel surge de la complejidad de la información, y por tanto, de la poca efectividad de los códigos con que opera cada individuo para descifrar adecuadamente la información. 
- Orientaciones de decisión: de la conjunción entre capacidad y recurso (aplicación de un código a la información) se deriva una acción a través de la cual se expresa el sentido que cada individuo atribuye a las probabilidades de inclusión, esto es, una codificación de la situación, observable empíricamente a través de una acción. Esta acción debe entenderse como una pretensión de inclusión y está mediada por la forma de coordinación que sustenta un mecanismo de protección social, en este caso el sistema de pensiones. La amenaza, en este sentido, refiere a que la acción que traduce la codificación propia de cada agente no se corresponda con la acción esperable según el principio de coordinación que incorpora el mecanismo de protección social. Por ejemplo, que el sistema disponga probabilidades de inclusión esperando que un individuo haga determinadas elecciones imputando una racionalidad que no se manifiesta en la práctica concreta.

Denominaremos estrategia a la combinación entre la información disponible, las capacidades de procesamiento y la orientación de decisión resultante. Respecto de la regla de acceso que tiene relación con la capacidad de gestión individual del riesgo (racionalidad), el sistema de pensiones de capitalización individual chileno actúa con los siguientes supuestos para los tres niveles de construcción de las respuestas individuales a los parámetros del sistema de pensiones:

- los individuos son capaces de tomar decisiones óptimas.

- los individuos tienen la información necesaria para tomar decisiones óptimas.

- los individuos se orientan hacia la toma de decisiones óptimas.

Este modelo restrictivo con el que opera el sistema de pensiones, que denominamos modelo de optimización, ha sido sucesivamente develado como inadecuado tanto para efectos de diseño como de análisis (Barr, 2000; Barr y Diamond, 2006). Los trabajos realizados por la SAFP, de hecho, dan cuenta de un traslado paulatino en el análisis y propuestas de reforma, desde un modelo de optimización hacia otro de optimización con información incompleta (Berstein y Ruiz, 2005; Berstein y Cabrita, 2006). En esta literatura se asume que por el sólo hecho de tener más información los individuos van a tomar las mejores elecciones, es decir, con un input razonable de información se puede lograr comportamientos cercanos a la racionalidad sustantiva tal como propone el modelo de optimización originalmente.

A nuestro juicio estos modelos siguen siendo inadecuados desde el punto de vista de la comprensión del operar de un sistema de pensiones como mecanismo de protección social, tal como lo hemos presentado. Siguiendo a Simon (1982) y el concepto de racionalidad procesal, podemos imaginar que los individuos se hacen una idea de beneficios satisfactorios que no necesariamente coinciden con los máximos beneficios alcanzables con la combinación óptima de decisiones. Se requiere, por tanto, no una ampliación del modelo de optimización para comprender el desempeño de un sistema de pensiones, sino su sustitución por un modelo que incorpore la noción de umbrales de satisfacción donde se pongan en juego las ideas de: existencia de capacidades de procesamiento disímiles, niveles de información desiguales y orientaciones de decisión diversas. ${ }^{13}$

El diagrama 4 muestra la clasificación que hemos hecho de este último nivel: 
Diagrama 4: Clasificación orientaciones de decisión

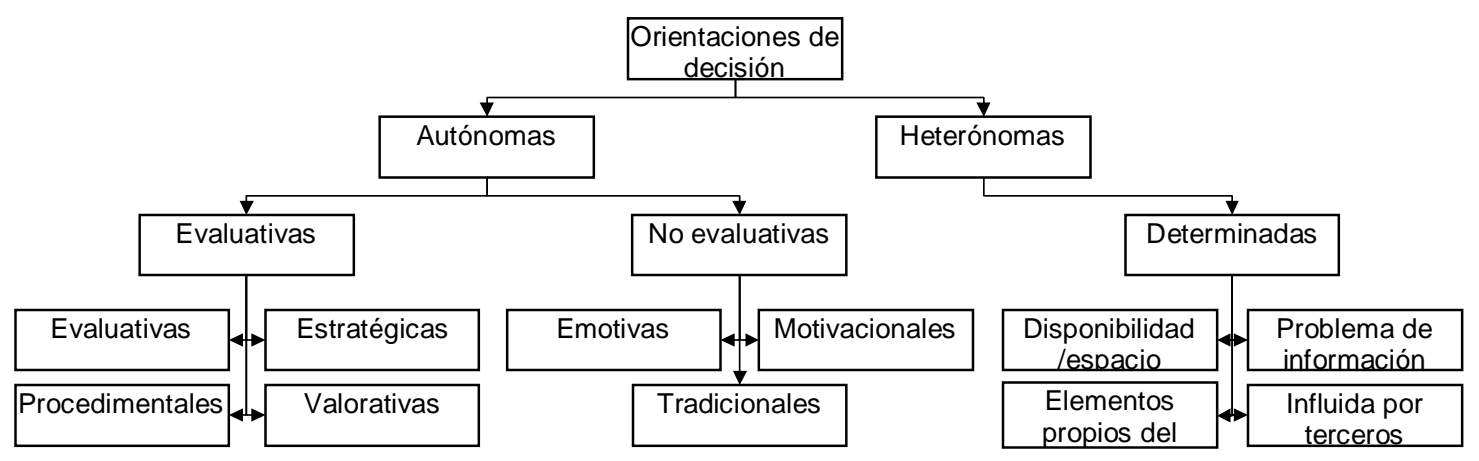

Fuente: Elaboración propia

\subsection{Síntesis del modelo de desempeño institucional}

A partir de lo hasta aquí planteado, podemos sintetizar nuestro modelo para evaluar el desempeño institucional de un sistema de pensiones. Este se compone de dos variables independientes o explicativas:

- Desempeño del mercado del trabajo: tiene relación con la movilización del recurso fuerza de trabajo que puede observarse a partir de un contrato de trabajo. Las disposiciones contenidas en el contrato se traducen en un ingreso, principal proxy de la protección social en el ámbito de las pensiones. Diferentes tipos de contrato generarán niveles de ingreso distintos que permitirán acceder a niveles de protección diferenciados.

- Desempeño de las decisiones individuales: tiene relación con los efectos de las decisiones individuales sobre los parámetros del sistema, de modo que diferentes estrategias generan decisiones distintas sobre variables relevantes, lo que permite acceder a niveles de protección diferenciados.

Estas variables pueden traducirse en dos factores que permiten clasificar los casos en un eje de coordenadas establecido según la distinción inclusión/exclusión.

- Factor estructural o medida de posición: tiene relación con el desempeño en el mercado del trabajo y permite ubicar los casos en los cuadrantes del esquema inclusión/exclusión presentado anteriormente.

- Factor individual o medida de variación: tiene relación con el desempeño de las decisiones individuales, y permite explicar las variaciones de los distintos casos clasificados en posiciones similares en un mismo cuadrante.

La distribución de los casos según lo anterior permitiría establecer una clasificación y descripción de las personas típicas asociadas a cada cuadrante entendidos como probabilidades similares de acceso a determinados niveles de protección social. ${ }^{14}$

Para el caso del indicador de desempeño calidad de la cobertura (la variable explicada), hemos identificado 4 formas de medición:

- Monto de la pensión: este indicador constituye el reflejo último del desempeño de cada una de las variables anteriores. Dado que no existen estadísticas suficientes pues aún el grueso de pensionados sigue estando a cargo del sistema antiguo, los montos de las pensiones deben ser proyectados según una serie de indicadores. ${ }^{15}$ 
- Tasa de reemplazo: consiste en el porcentaje que representa la pensión respecto del último sueldo. Si bien la tasa de reemplazo se construye teniendo el dato del monto de la pensión, este tiene la ventaja de no presentar una medida continua sino de razón, lo que permite establecer cortes y así generar clasificaciones.

- Densidad de cotizaciones: en vistas de que los indicadores anteriores parecen demasiado exigentes metodológicamente hablando, se ofrece la posibilidad de recurrir a un tercer indicador que es considerado con un alto nivel predictivo de los montos de la pensión a obtener, y por tanto también de las tasas de reemplazo. La densidad de cotizaciones refleja los patrones de aportes mensuales que las personas realizan en sus cuentas de capitalización de modo que consiste en un buen resumen de diversos determinantes del monto de las pensiones como las variaciones de ingresos, los cambios laborales de las personas (entradas y salidas de la fuerza de trabajo, movimientos desde trabajos dependientes a independientes), etc.

- Porcentaje de una pensión base: corresponde a un indicador que nos ofrece una medida de la desigualdad de los montos de las pensiones que obtienen distintas personas. Permite, así, un análisis del desempeño del sistema en virtud de las diferencias en los montos de las pensiones obtenidos por las personas. Hemos identificado dos indicadores, el de la PBS (Pensión Básica Solidaria) que alcanzará $\$ 75.000$ pesos cuando entre plenamente en vigencia el año 2009 y el de la PMAS (Pensión Máxima con Aporte Solidario) cuyo valor será de $\$ 250.000$ cuando entre en vigencia en 2012.

\section{TERCER PASO: DESEMPEÑO I NSTI TUCI ONAL DEL SI STEMA DE PENSI ONES CHI LENO}

A continuación se presentan los resultados de la aplicación del marco analítico explicitado en la sección anterior. La metodología utilizada consistió en tomar las historias previsionales levantadas por la Encuesta de Protección Social de la ola 2006, y en base a los comportamientos previsionales de las personas proyectar cuales serían sus pensiones iniciales si se mantuvieran constantes todos los parámetros y se homogenizan las condiciones de salida del mercado del trabajo. Los resultados son representativos del stock de pensionados que se jubilará entre los años 2027 a 2047.

\section{Mercado del trabajo}

\subsection{Género}

Los resultados indican que del stock de pensionados del periodo de referencia (20272047) un 44\% obtendrá una pensión inferior al valor de la Pensión Básica Solidaria (PBS), situación que entre las mujeres llegará al 61\%, mientras que entre los hombres será de un $25 \%$ (ver gráfico 1 ). En el polo contrario se observa que sólo un $2 \%$ de las mujeres obtendrá una pensión por sobre el valor de dos Pensiones máximas con aporte solidario (PMAS), mientras que entre los hombres dicho porcentaje llegará al $14 \%$. Desde el punto de vista de las tasas de reemplazo ${ }^{16}$ esto implica que un $65 \%$ de los hombres y tan sólo un $20 \% \%$ de las mujeres llegará a una tasa de reemplazo ${ }^{17}$ superior al $50 \%$, lo que para el stock de pensionados representa un $46.1 \%$ (ver gráfico 2). 
Gráfico 1: Monto de la pensión inicial proyectada según sexo

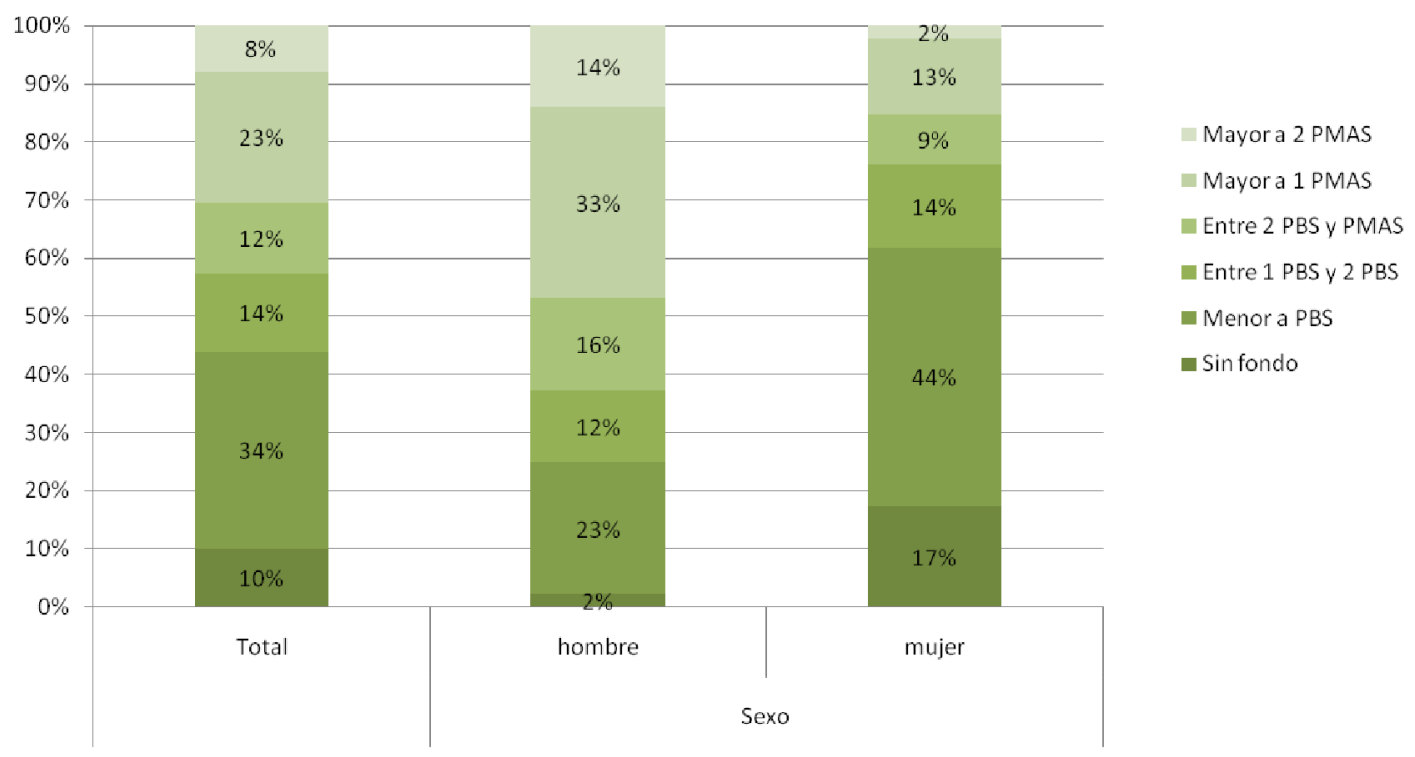

Fuente: Elaboración propia en base a datos EPS (2006)

Gráfico 2: Monto de la tasa de reemplazo proyectada según sexo

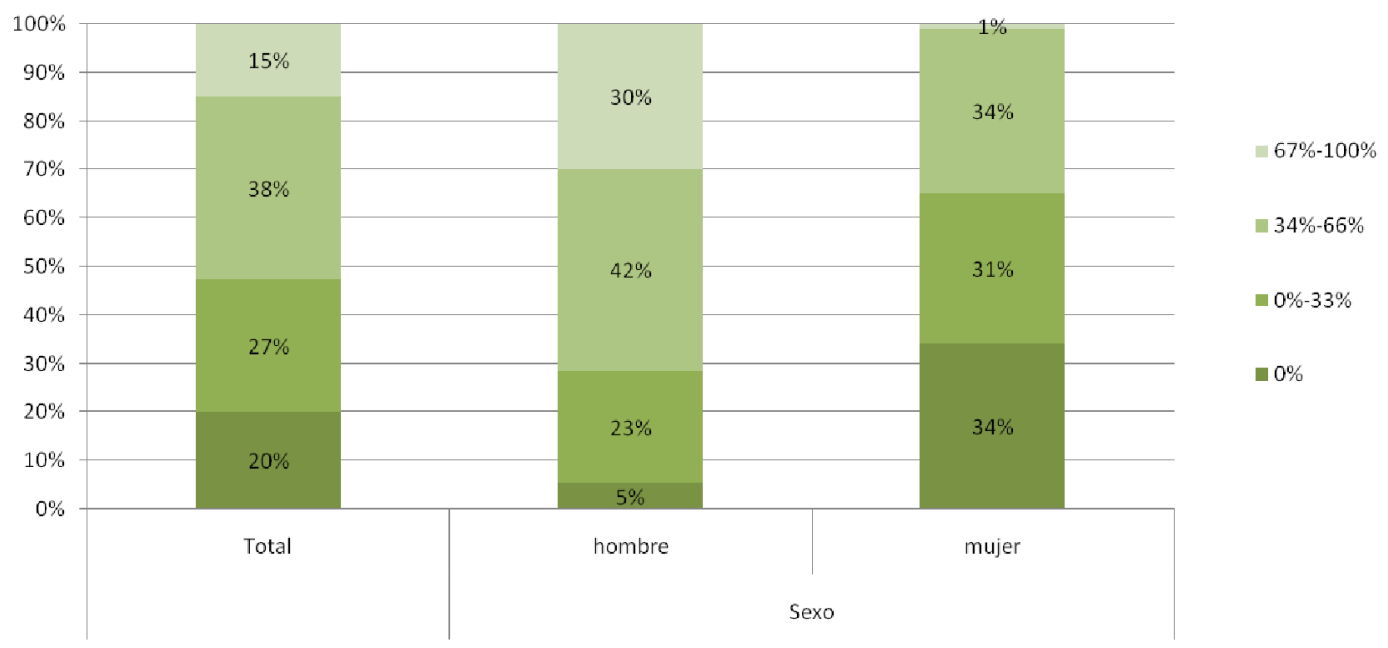

Fuente: Elaboración propia en base a datos EPS (2006)

Como vemos, las diferencias por género son importantísimas ya que en promedio las tasas de reemplazo de los hombres duplican a la de las mujeres ( $53 \%$ contra $23 \%$ ) y las pensiones promedio obtenidas por los hombres son 2,82 veces superiores a la de las mujeres (ver gráfico 3 ). En general las diferencias por género son transversales a cualquier otra variable y muestran el claro desmedro en que se encuentran las mujeres en lo referente a las pensiones de vejez. 


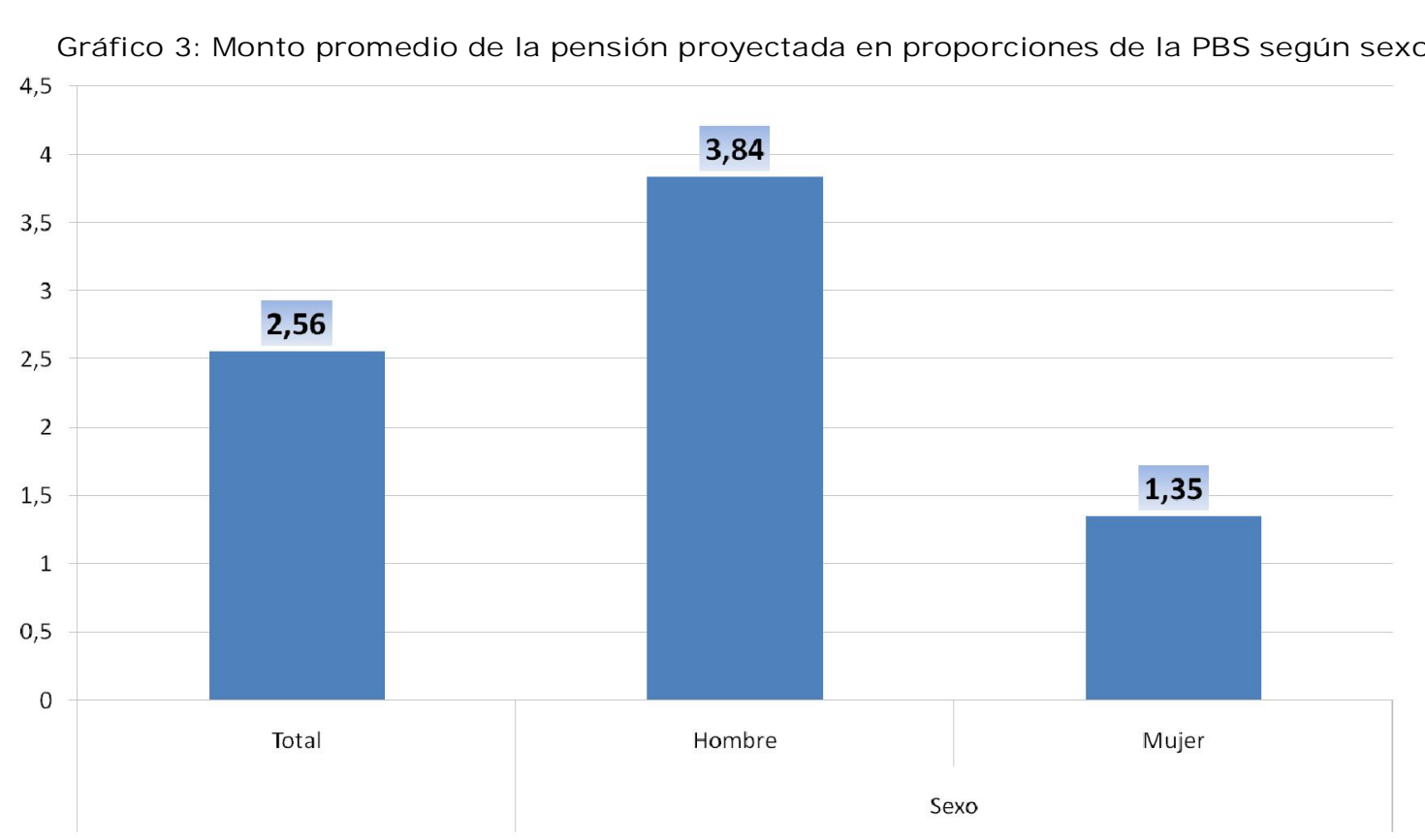

Fuente: Elaboración propia en base a datos EPS (2006)

\subsection{Nivel educacional}

La educación tiene un efecto diferenciador de los resultados previsionales de las personas. A medida que ascendemos en los niveles educacionales observamos una clara progresión del nivel de protección obtenido: quienes tienen educación media incompleta o menos tienen una proporción mayor al $50 \%$ de personas que tendrán pensiones inferiores a una PBS. Del otro lado de la distribución, entre quienes tienen educación universitaria completa y postgrado al menos un $50 \%$ alcanzará pensiones superiores a la PMAS. Las diferencias entre las pensiones promedio obtenidas por quienes tienen postgrado y quienes no alcanzan siquiera la educación básica formal es de alrededor de 14 veces (gráfico 4). 
Nuevas aproximaciones para el análisis de sistemas de protección social: La noción de desempeño institucional y su aplicación al sistema de pensiones chileno

Gráfico 4: Monto de la pensión proyectada según nivel educacional

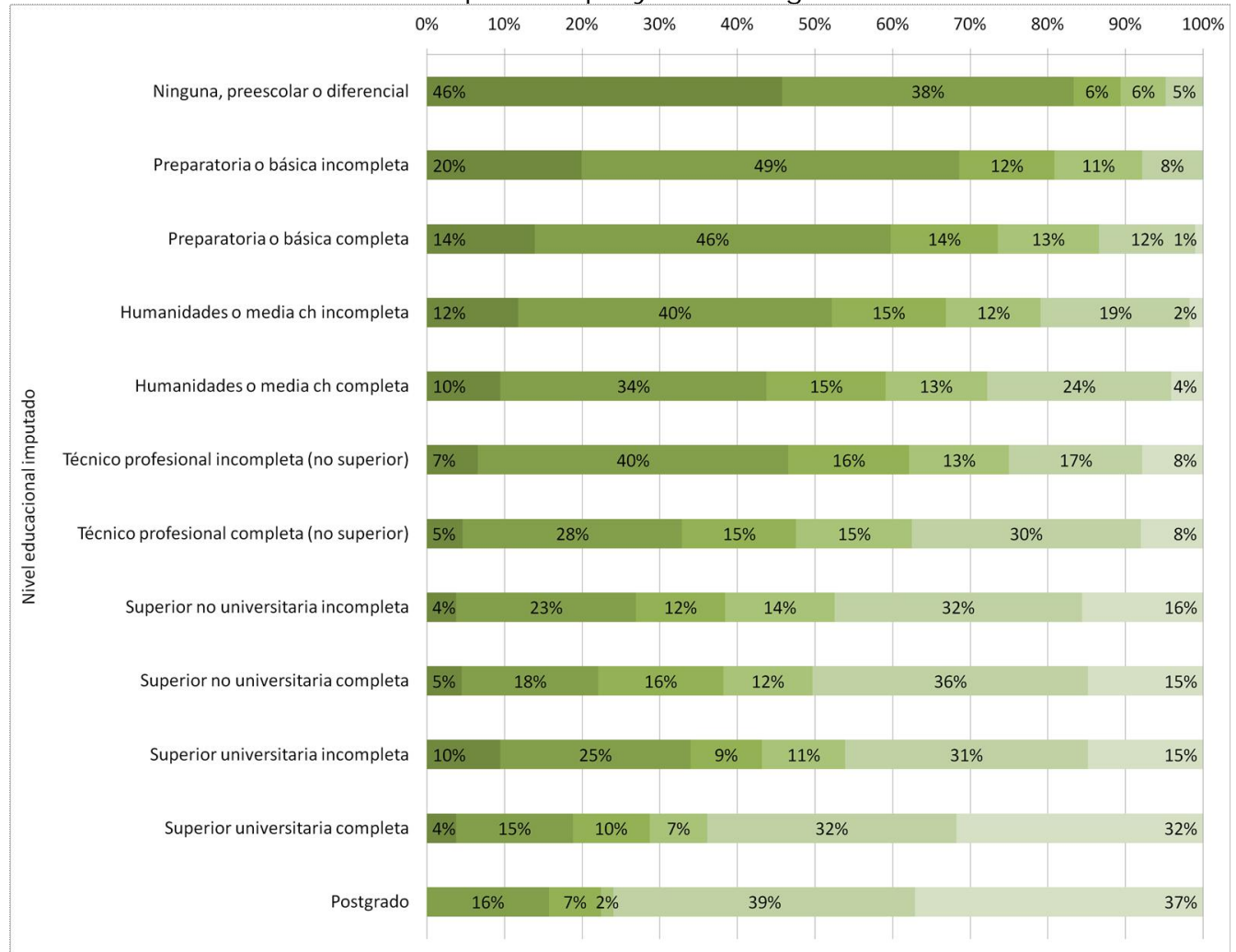

- Sin fondo $₫$ Menor a PBS $₫$ Entre 1 PBS y 2 PBS $₫$ Entre 2 PBS y PMAS $₫$ Mayor a 1 PMAS $₫$ Mayor a 2 PMAS

Fuente: Elaboración propia en base a datos EPS (2006)

Gráfico 5: Tasa de reemplazo proyectada según nivel educacional

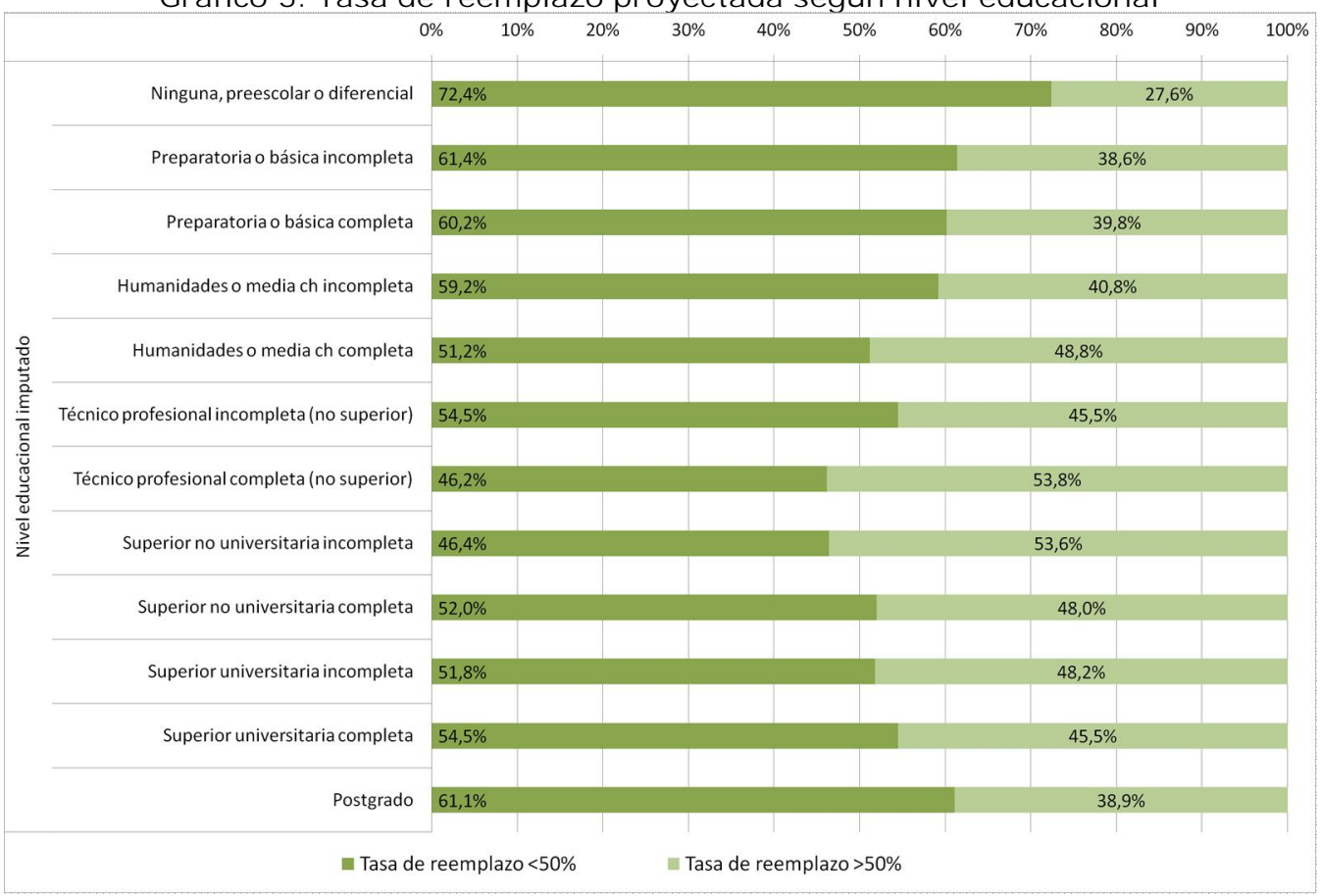

Fuente: Elaboración propia en base a datos EPS (2006)

Revista Mad. N²0, Mayo de 2009. Departamento de Antropología. Universidad de Chile http://www.revistamad.uchile.cl/20/madariaga_01.pdf 
La distribución de las tasas de reemplazo se presenta menos desigual de lo que puede observarse en base al monto de la pensión inicial; esto sucede debido a que la dispersión de la densidad de cotización, principal determinante de la tasa de reemplazo, es menor que la de los salarios. Sin embargo, existen también diferencias importantes: entre quienes no tienen educación formal sólo un $27 \%$ supera el $50 \%$ de tasa de reemplazo. Una vez que se supera la educación media completa (o humanidades completa), existe al menos un $45 \%$ de personas que obtendrán una tasa de reemplazo superior al $50 \%$, excepto entre quienes tienen posgrado.

\subsection{Diferencias ocupacionales}

Las diferencias por ocupación son altamente segmentadas. Existe una serie de ocupaciones en que más de un $30 \%$ de personas obtiene pensiones inferiores a la PBS, siendo principalmente afectados aquellos que trabajan como independientes y quienes tienen baja calificación ${ }^{18}$ : El grupo de ocupaciones que aparecen como más protegidas pueden ser identificadas en términos de aquellas en que al menos un $50 \%$ de las personas que lo componen obtendrían pensiones superiores a la PMAS. Dichas ocupaciones son los empleados de nivel medio y alto del sector público, los operarios y montadores de instalaciones y maquinarias, los oficiales y operarios de las artes mecánicas del sector privado, los técnicos y profesionales de nivel medio del sector privado y los profesionales científicos e intelectuales del sector privado (gráfico 6).

Gráfico 6: Monto de pensión proyectada según ocupación

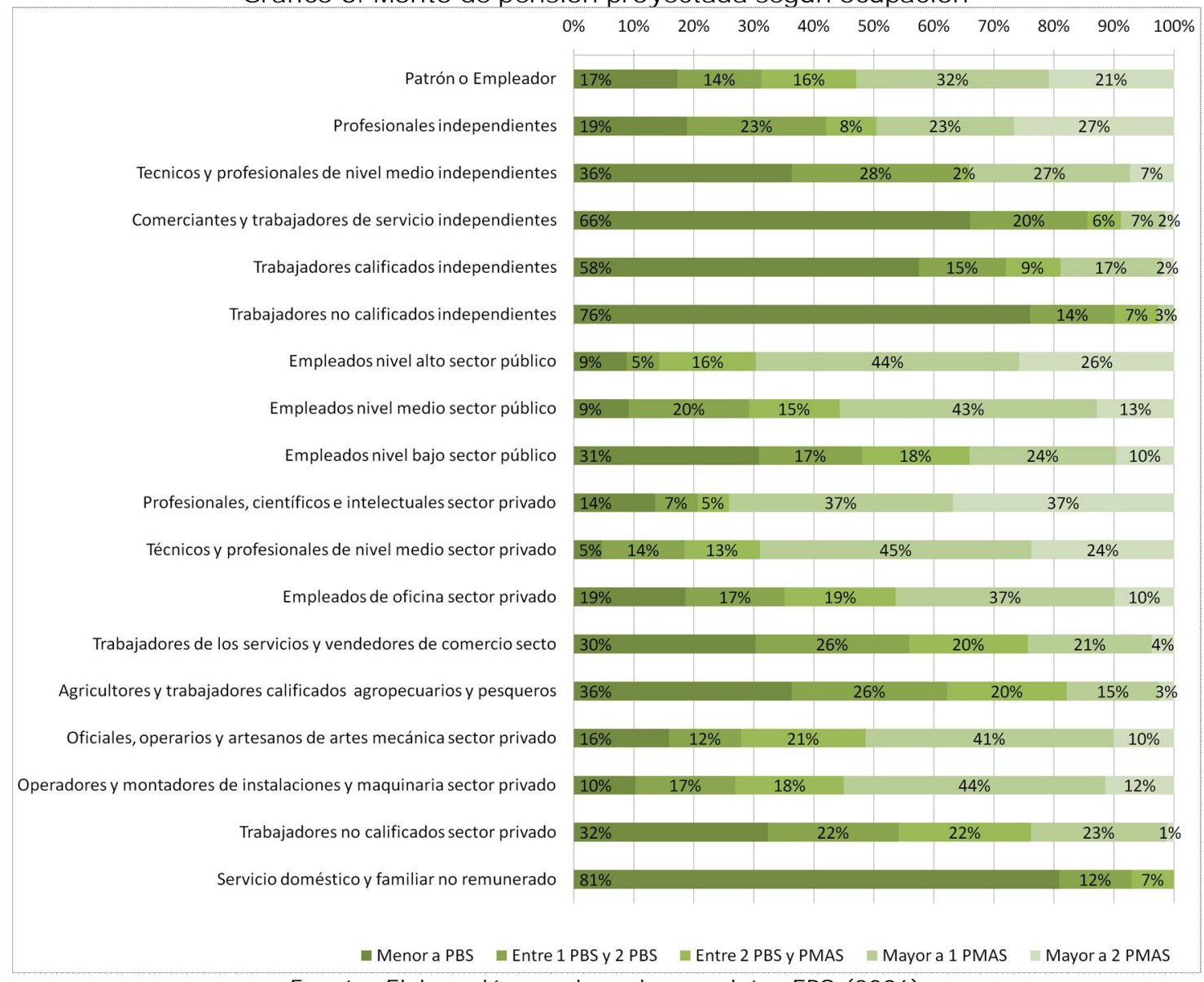

Fuente: Elaboración propia en base a datos EPS (2006)

Revista Mad. N²0, Mayo de 2009. Departamento de Antropología. Universidad de Chile http://www. revistamad.uchile.cl/20/madariaga_01.pdf 
Como se puede observar, mejores resultados previsionales se asocian con tres factores en el mercado del trabajo: (a) por una parte, la dependencia del sector público por sobre el privado aumenta el estándar de protección a niveles similares de especialización; (b) la especialización de las habilidades genera una situación de mejor protección futura; y (c) la independencia laboral es un fuerte factor de vulnerabilidad en el sistema.

Al observar las tasas de reemplazo podemos ver que la segmentación de las ocupaciones es diferente a la arrojada en base al monto de las pensiones. Por un lado, existen ocupaciones en que más de de la mitad de las personas obtienen tasas de reemplazo superiores al 50\%: Patrones y empleadores, Técnicos y profesionales de nivel medio sector privado, Oficiales, operarios y artesanos de artes mecánica sector privado, Operadores y montadores de instalaciones y maquinaria, Trabajadores nivel bajo sector público y Trabajadores calificados sector privado (gráfico 7).

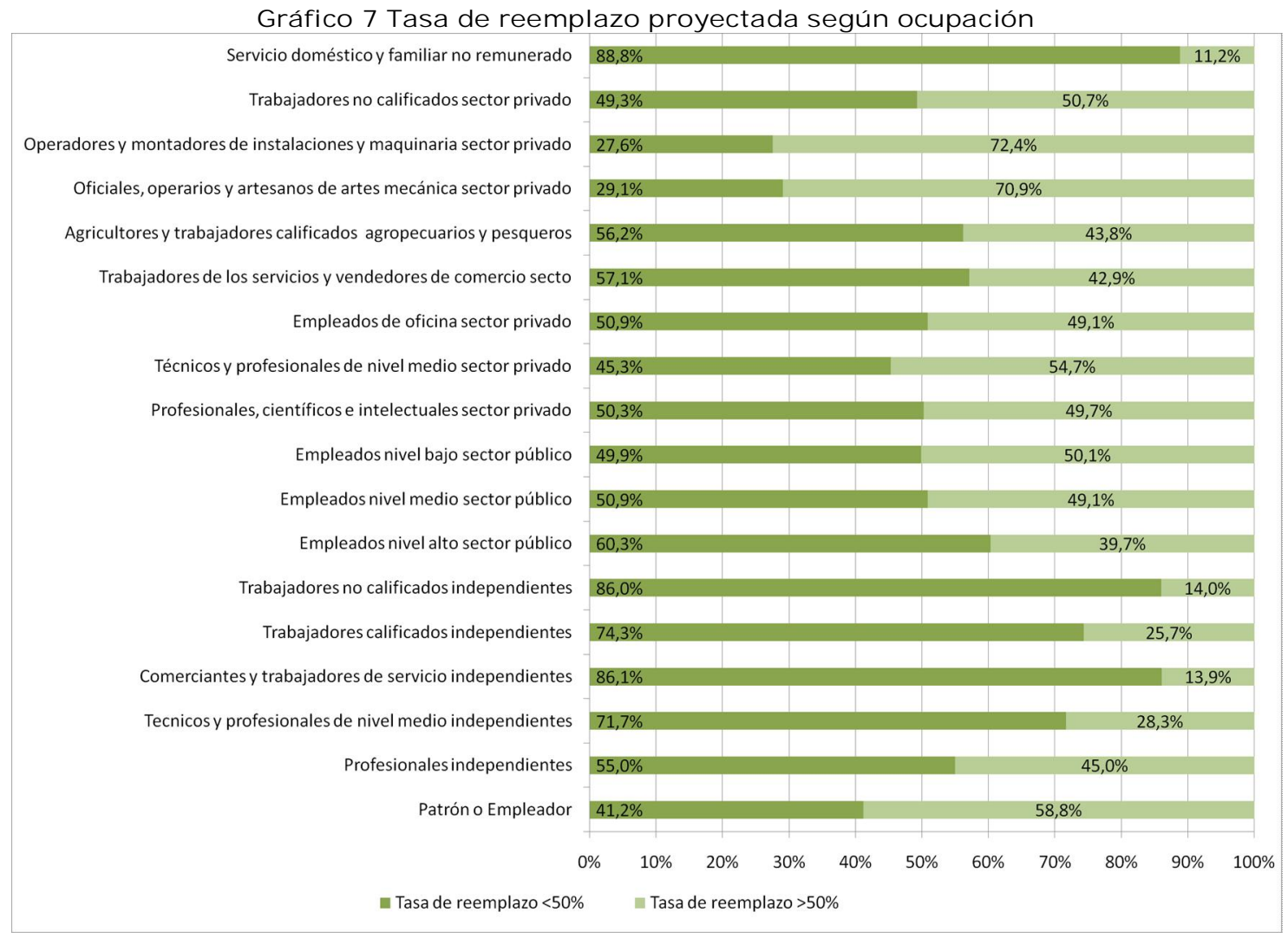

Fuente: Elaboración propia en base a datos EPS (2006)

En el lado contrario vemos que entre los Técnicos y profesionales de nivel medio independientes, Comerciantes y trabajadores de servicio independientes, Trabajadores no calificados independientes, Trabajadores no calificados independientes y el servicio doméstico y familiar no remunerado, más de un $70 \%$ de las personas recibirán pensiones con tasas de reemplazo inferiores al $50 \%$. 


\section{Estrategias individuales}

Al observar los resultados previsionales estos muestran, en general, ser sensibles a las diferencias de capacidades no cognitivas de procesamiento de la información, a la información poseída y a las orientaciones de decisión detrás de las motivaciones expuestas por los entrevistados en distintas preguntas referentes a su comportamiento previsional.

En efecto, en el global de los casos podemos observar que existe asociación entre las variables mencionadas y los montos de pensión y las tasas de reemplazo. La variable que tiene una asociación mayor con respecto a las tasas de reemplazo y montos de pensión obtenida es la información poseída sobre el sistema provisional. Si se toman dos grupos diferenciados por el grado de información que manejan del sistema previsional ${ }^{19}$, aquellos que están en el grupo con menor información tienen en promedio tasas de reemplazo del orden del 38\%, mientras que quienes manejan más información, las tasas de reemplazo suben hasta el $49 \%$ promedio (gráfico 8 ).

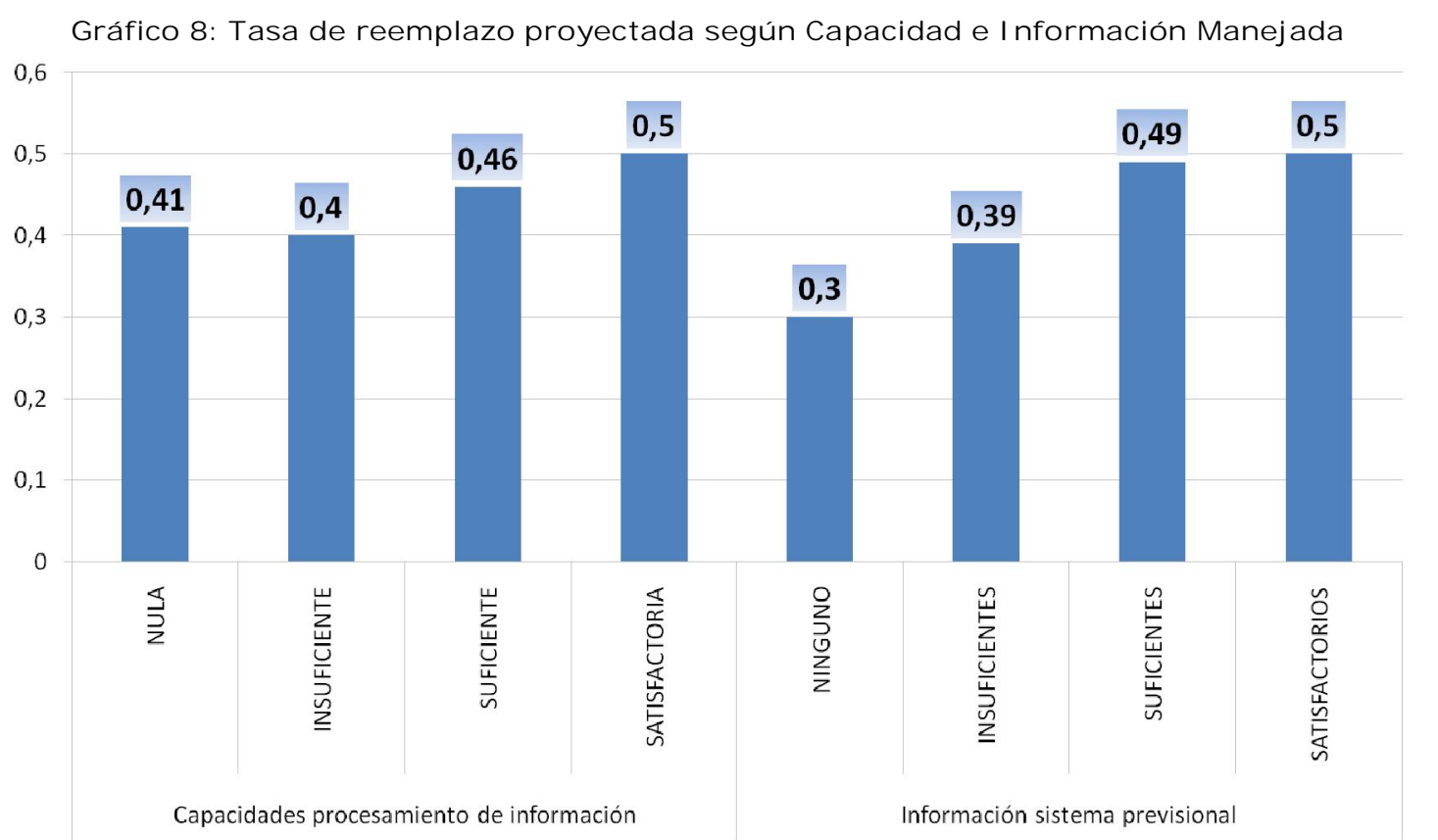

Fuente: Elaboración propia en base a datos EPS (2006)

En la misma división de posesión de información en dos grupos, los montos de la pensión pasan de un $140 \%$ promedio de la PBS para quienes poseen menos información a un $370 \%$ promedio para quienes poseen más información (gráfico 9). 


\section{Gráfico 9: Monto de la pensión promedio proyectada como proporción de la PBS según Capacidad e I nformación Manejada}

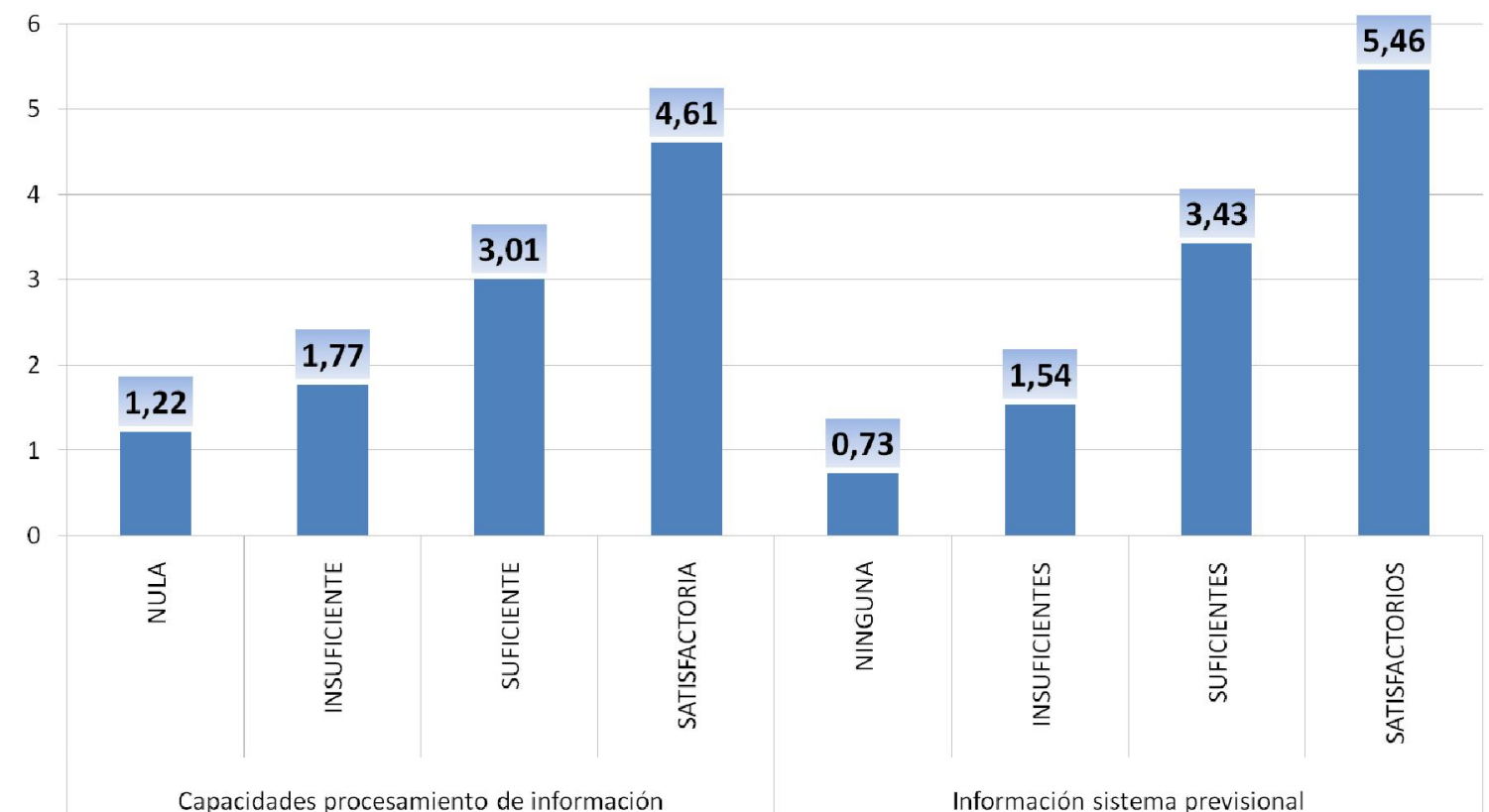

Fuente: Elaboración propia en base a datos EPS (2006)

Entre quienes demuestran nulas habilidades cognitivas y quienes demuestran tener habilidades satisfactorias (el rango más alto) existe una diferencia de 3,77 veces en los montos de la pensión recibida a favor de estos últimos. En términos de las tasas de reemplazo, las diferencias se atenúan, llegado tan sólo 1,22 veces a favor de quienes están en el tramo más alto de la escala de capacidades no cognitivas (gráfico 8).

Al observar la agrupación formada por el cruce de la variable información con la variable capacidad (gráfico 10), podemos observar de manera más clara que, a igualdad de densidad de cotizaciones, para el general de casos los montos de las pensiones mejoran al poseerse las dos características, es decir, quienes tienen información y capacidades para procesar dicha información logran mayores montos de pensión. Dicha característica no es clara en el caso de la tasa de reemplazo, aunque en el total de los casos se observa una tendencia a favor de los más capacitados para tomar decisiones. 
Gráfico 10: Desempeño según tramos Densidad de cotizaciones y disposición ${ }^{20}$

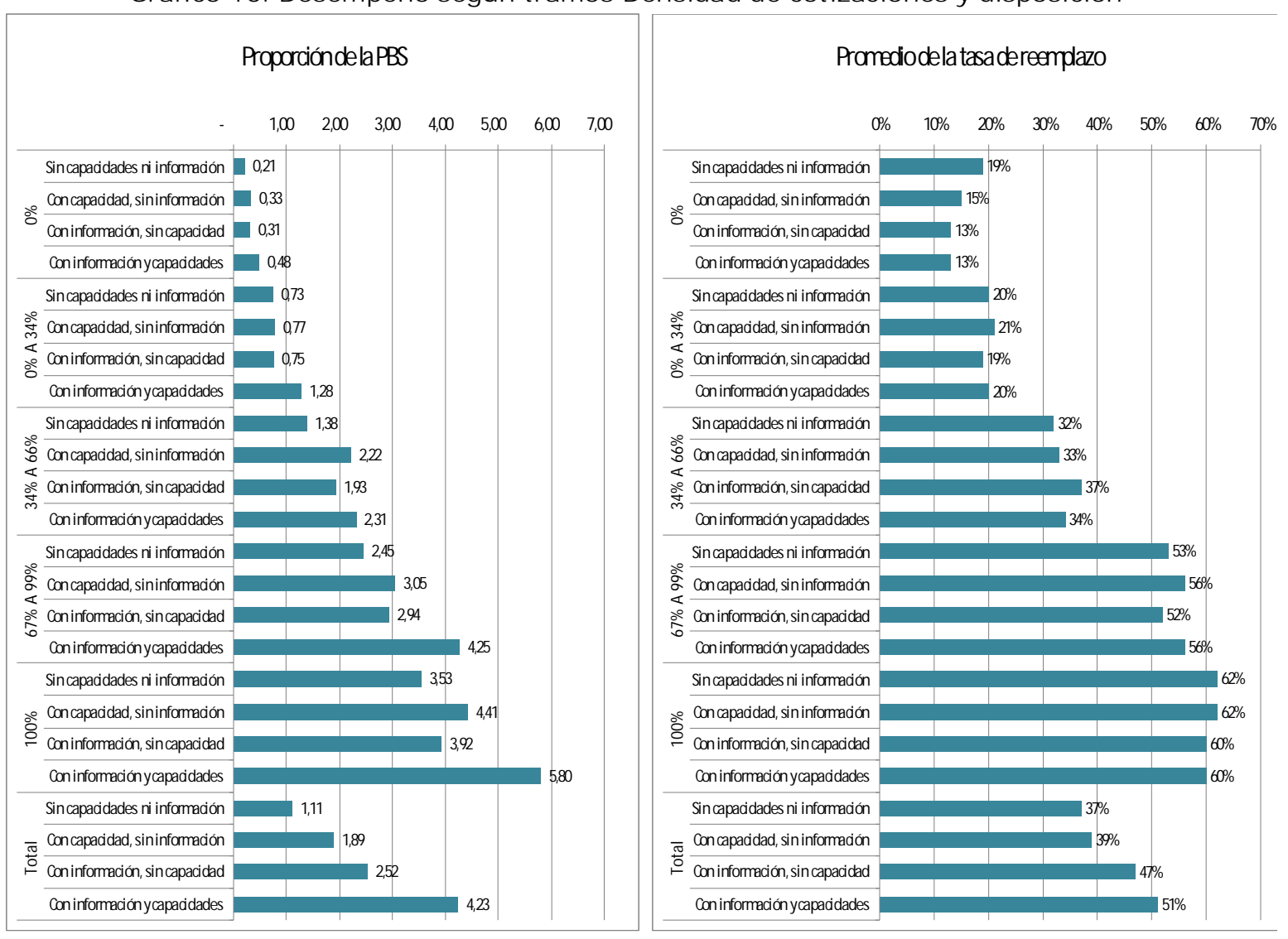

Fuente: Elaboración propia en base a datos EPS (2006)

A niveles iguales de ingreso se confirma la tendencia de que personas más capacitadas mejoran sus resultados previsionales (gráfico 11 ).

Revista Mad. $\mathrm{N}^{\circ}$ 20, Mayo de 2009. Departamento de Antropología. Universidad de Chile 


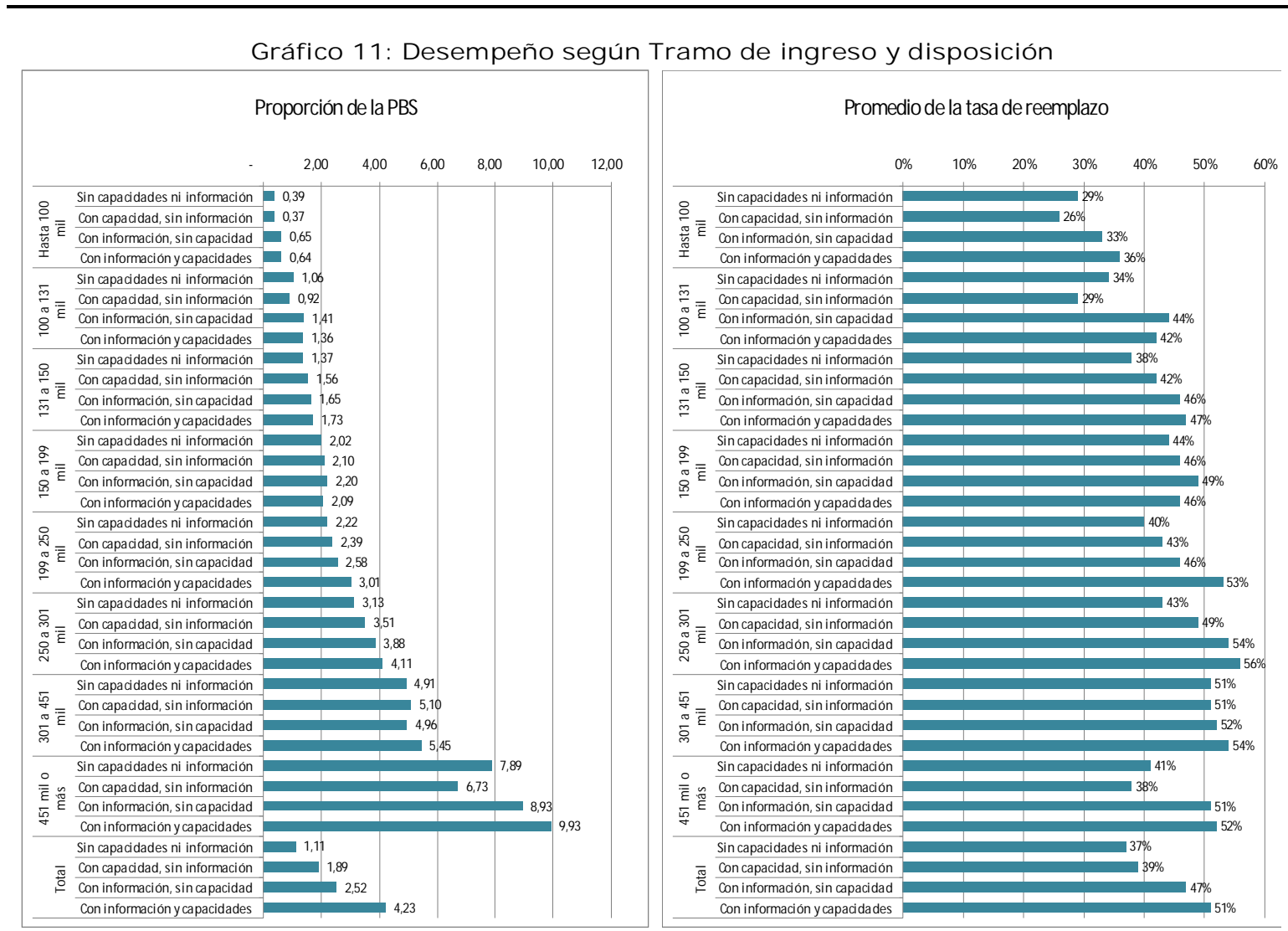

Fuente: Elaboración propia en base a datos EPS (2006)

Cuando observamos las diferencias de resultados en relación a las orientaciones manifestadas por los individuos con respecto a sus comportamientos previsionales, también podemos identificar diferencias. Si nos quedamos con la primera clasificación de tres tipos de orientaciones de decisión, evaluativas, no evaluativas y determinadas, podemos observar que la presencia de una de ellas tiene efectos diferenciadores con respecto a los resultados obtenidos: en términos de los montos de pensión logrados, vemos que quienes presentan orientaciones determinadas alcanzan un promedio 2,93 PBS, quienes presentan orientaciones no evaluativas, el promedio asciende levemente a 3,12 PBS, sin embargo, cuando pasamos a quienes presentan decisiones evaluativas, el promedio sube a 3,85 PBS (gráfico 12). 
Gráfico 12: Desempeño según Densidad de cotizaciones y tipo de orientación

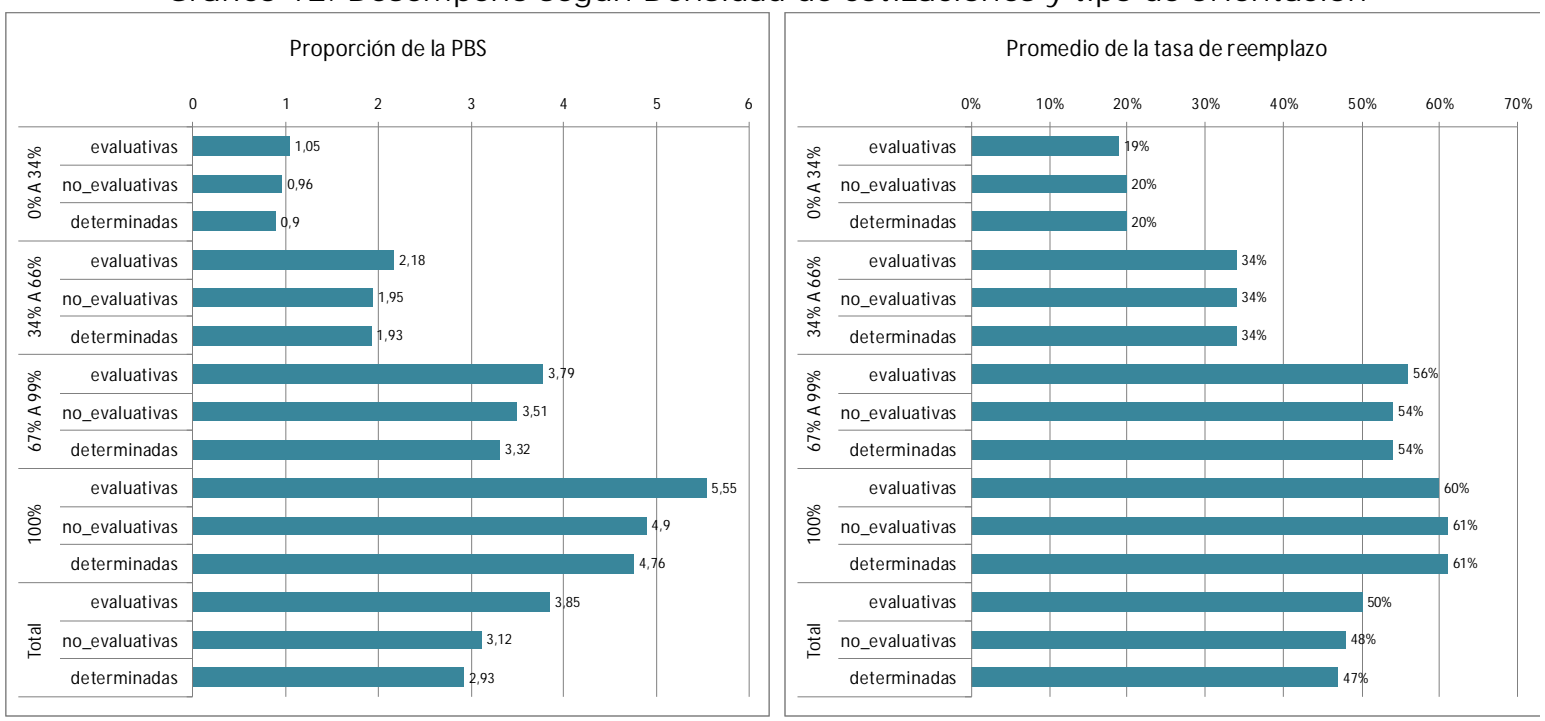

Fuente: Elaboración propia en base a datos EPS (2006)

Diferencias existen también en las tasas de reemplazo, sin embargo estas son menos pronunciadas: orientaciones no evaluativas y determinadas alcanzan un promedio de $48 \%$ y $47 \%$ respectivamente, mientras que entre quienes muestran orientaciones evaluativas las tasas de reemplazo suben a un 50\% promedio (gráfico 12 y 13). Es relevante destacar que los universos de personas con diferentes orientaciones de decisión son diferentes; orientaciones determinadas son manifestadas por el $73,7 \%$ de la muestra, las orientaciones no evaluativas son manifestadas por casi el $65,3 \%$ de la muestra, mientras que tan sólo el $31 \%$ de la muestra manifiesta decisiones evaluativas. De este modo, la segmentación resulta relevante, pues el bien al cual se asocian mejores resultados previsionales, es a la vez, el más escaso. 


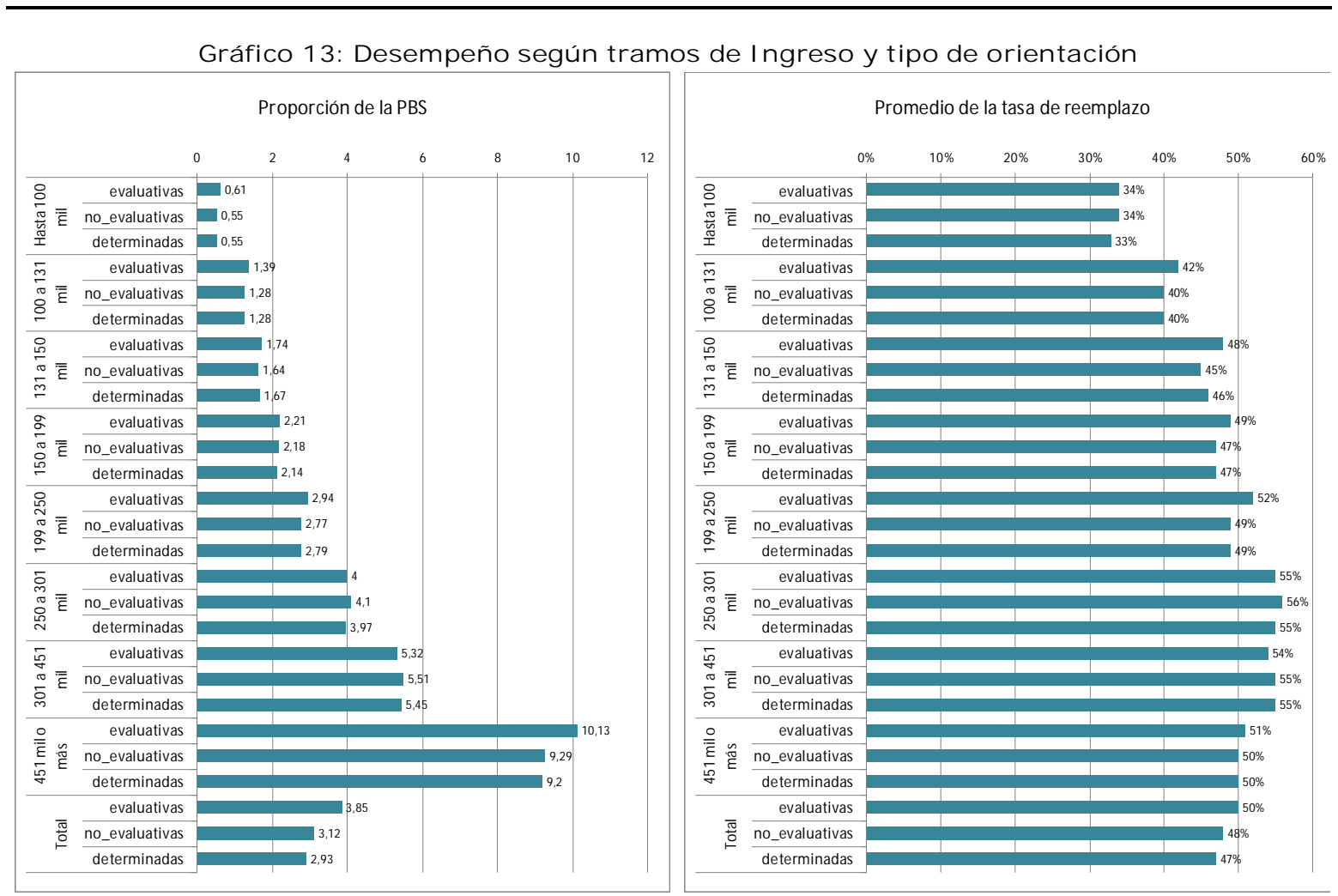

Fuente: Elaboración propia en base a datos EPS (2006)

Estos resultados nos indican que junto con las orientaciones de decisión son variables relevantes en los resultados previsionales tanto las capacidades de procesar información como la obtención de esta. Sin embargo, estas relaciones se encuentran mediadas por la influencia del nivel educacional y los resultados que provoca este factor en la obtención de mejores puestos en el mercado del trabajo, que a través de mejores retribuciones y una mayor estabilidad, tienden a asegurar mejores beneficios en la vejez.

\section{Síntesis resultados}

Al observar la interacción de las variables en análisis podemos ver que la segmentación en el acceso al mercado del trabajo tiende a formar tres grupos según sus resultados previsionales. Por un lado podemos apreciar que existe un grupo de beneficiarios para los cuales el sistema parece funcionar relativamente bien -que son re-incluidos exitosamente, en segundo lugar habría un gran espacio donde los resultados previsionales son ampliamente diversos generando situaciones de inclusión espuria y posiciones con diversos grados de vulnerabilidad, y un tercer grupo en que los resultados son completamente adversos generando una clara situación de exclusión ( ver gráfico № 14). 
Gráfico $14^{21}$. Análisis de correspondencias zonas de inclusión

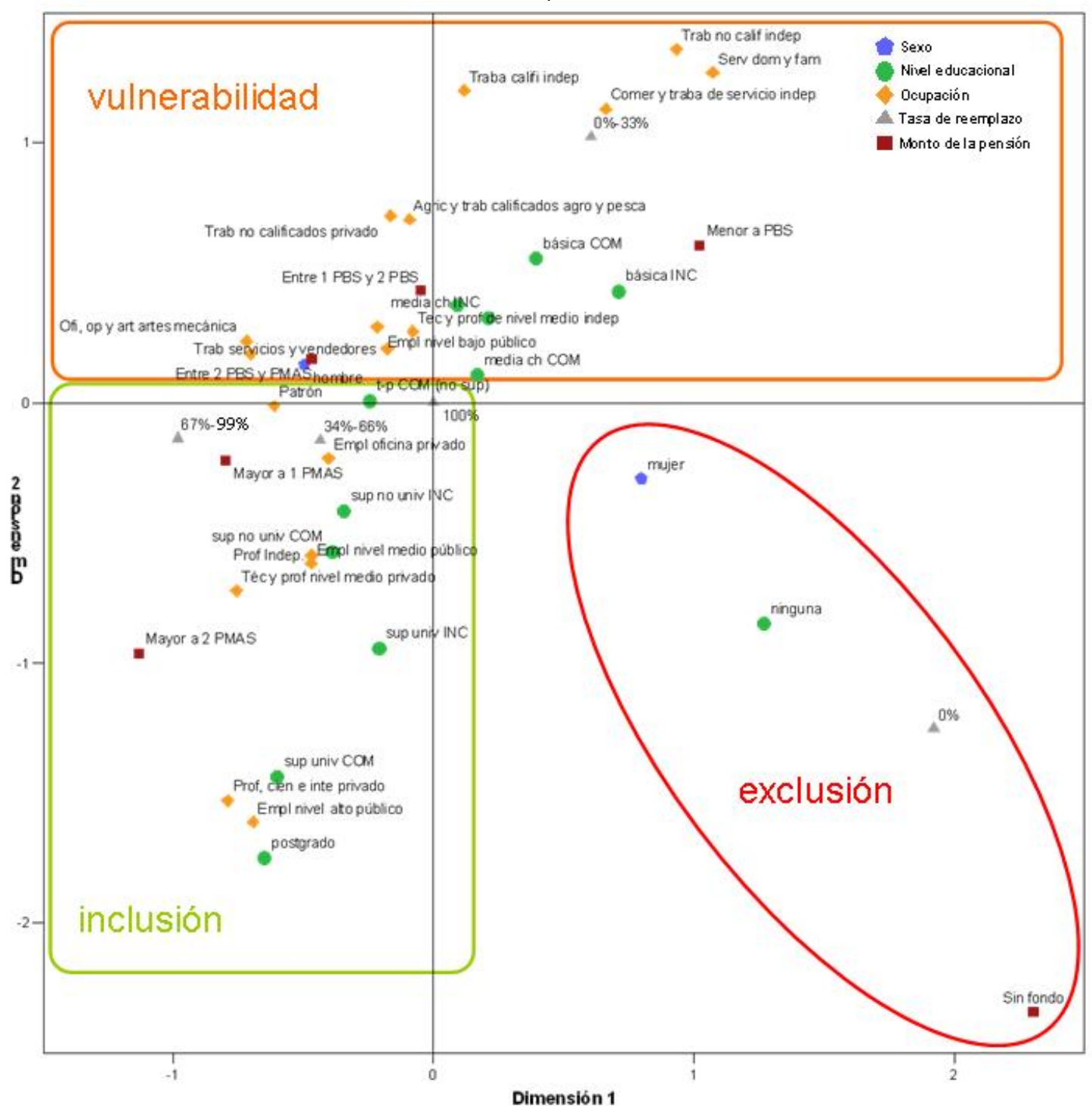

\begin{tabular}{|c|c|c|c|}
\hline \multicolumn{4}{|c|}{ Claves } \\
\hline \multicolumn{2}{|c|}{ Ocupaciones } & \multicolumn{2}{|c|}{ Nivel educacional } \\
\hline Patrón & Patrón o Empleador & ninguna & $\begin{array}{lll}\text { Ninguna, } & \text { preescolar } & 0 \\
\text { diferencial }\end{array}$ \\
\hline Prof Indep. & Profesionales independientes & básica INC & $\begin{array}{l}\text { Preparatoria } \\
\text { incompleta }\end{array}$ \\
\hline $\begin{array}{l}\text { Tec y prof de nivel } \\
\text { medio indep }\end{array}$ & $\begin{array}{l}\text { Técnicos y profesionales de } \\
\text { nivel medio independientes }\end{array}$ & básica COM & $\begin{array}{l}\text { Preparatoria o básica } \\
\text { completa }\end{array}$ \\
\hline $\begin{array}{l}\text { Comer y traba de } \\
\text { servicio indep }\end{array}$ & $\begin{array}{l}\text { Comerciantes y trabajadores } \\
\text { de servicio independientes }\end{array}$ & media ch INC & $\begin{array}{l}\text { Humanidades o media ch } \\
\text { incompleta }\end{array}$ \\
\hline Traba califi indep & $\begin{array}{ll}\text { Trabajadores } & \text { calificados } \\
\text { independientes } & \\
\end{array}$ & media ch COM & $\begin{array}{l}\text { Humanidades o media ch } \\
\text { completa }\end{array}$ \\
\hline Trab no calif indep & $\begin{array}{l}\text { Trabajadores no calificados } \\
\text { independientes }\end{array}$ & $\begin{array}{l}\mathrm{t}-\mathrm{p} \quad \mathrm{INC} \\
\text { superior) }\end{array}$ & $\begin{array}{ll}\text { Técnico } & \text { profesional } \\
\text { incompleta (no superior) }\end{array}$ \\
\hline $\begin{array}{lll}\text { Empl } & \text { nivel alto } \\
\text { público } & & \\
\end{array}$ & $\begin{array}{l}\text { Empleados nivel alto sector } \\
\text { público }\end{array}$ & 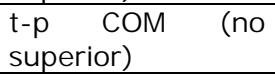 & $\begin{array}{l}\text { Técnico profesional } \\
\text { completa (no superior) }\end{array}$ \\
\hline $\begin{array}{l}\text { Empl nivel medio } \\
\text { público }\end{array}$ & $\begin{array}{l}\text { Empleados nivel medio sector } \\
\text { público }\end{array}$ & $\begin{array}{l}\text { sup } \\
\text { universitaria INC }\end{array}$ & $\begin{array}{l}\text { Superior no universitaria } \\
\text { incompleta }\end{array}$ \\
\hline Empl nivel & Empleados nivel bajo sector & sup no & Superior no universitaria \\
\hline
\end{tabular}

Revista Mad. N 20, Mayo de 2009. Departamento de Antropología. Universidad de Chile http://www. revistamad.uchile.cl/20/madariaga_01.pdf 
Nuevas aproximaciones para el análisis de sistemas de protección social: La noción de desempeño institucional y su aplicación al sistema de pensiones chileno

\begin{tabular}{|c|c|c|c|}
\hline público & público & universitaria COM & completa \\
\hline $\begin{array}{l}\text { Prof, cien e inte } \\
\text { privado }\end{array}$ & $\begin{array}{lcc}\text { Profesionales, científicos } & \text { e } \\
\text { intelectuales sector privado }\end{array}$ & $\begin{array}{l}\text { sup universitaria } \\
\text { INC }\end{array}$ & $\begin{array}{ll}\text { Superior } & \text { universitaria } \\
\text { incompleta } & \\
\end{array}$ \\
\hline $\begin{array}{l}\text { Téc y prof nivel } \\
\text { medio privado }\end{array}$ & $\begin{array}{l}\text { Técnicos y profesionales de } \\
\text { nivel medio sector privado }\end{array}$ & $\begin{array}{l}\text { sup universitaria } \\
\text { COM }\end{array}$ & $\begin{array}{ll}\begin{array}{l}\text { Superior } \\
\text { completa }\end{array} & \text { universitaria } \\
\end{array}$ \\
\hline Empl oficina privado & $\begin{array}{l}\text { Empleados de oficina sector } \\
\text { privado }\end{array}$ & postgrado & Postgrado \\
\hline $\begin{array}{l}\text { Trab servicios y } \\
\text { vendedores }\end{array}$ & $\begin{array}{l}\text { Trabajadores de los servicios } \\
\text { y vendedores de comercio } \\
\text { sector privado }\end{array}$ & & \\
\hline $\begin{array}{lrr}\text { Agric } & \text { y } & \text { trab } \\
\text { calificados } & \text { agro } & y \\
\text { pesca } & & \end{array}$ & $\begin{array}{l}\text { Agricultores y trabajadores } \\
\text { calificados agropecuarios y } \\
\text { pesquero }\end{array}$ & & \\
\hline $\begin{array}{l}\text { Ofi, op y art artes } \\
\text { mecánica }\end{array}$ & $\begin{array}{l}\text { Oficiales, operarios y } \\
\text { artesanos de artes mecánica } \\
\text { sector pricvdo }\end{array}$ & & \\
\hline $\begin{array}{l}\text { Ope y monta instal y } \\
\text { maqu }\end{array}$ & $\begin{array}{l}\text { Operadores y montadores de } \\
\text { instalaciones y maquinaria } \\
\text { sector }\end{array}$ & & \\
\hline $\begin{array}{l}\text { Trab no calificados } \\
\text { privado }\end{array}$ & $\begin{array}{l}\text { Trabajadores no calificados } \\
\text { sector privado }\end{array}$ & & \\
\hline Serv dom y fam & $\begin{array}{l}\text { Servicio doméstico y familiar } \\
\text { no remunerado }\end{array}$ & & \\
\hline Patrón & Patrón o Empleador & & \\
\hline
\end{tabular}

Resulta relevante destacar que las diferentes estrategias individuales (combinación de información poseída, capacidades no cognitivas y orientaciones de decisión), ofrecen, dentro de cada segmento, una diferenciación adicional a la establecida por el mercado del trabajo, pues dentro de cada tramo de ingreso y cada tramo de densidad de cotizaciones (es decir, bajo condiciones similares) podemos encontrar diferencias que indicarían que estas variables tienen un peso real en los resultados previsionales. Tanto a igualdad de ingreso como de densidad de cotizaciones se encuentran diferencias asociadas a estas variables que, a pesar de ser relativamente débiles, muestran una tendencia a aumentar cuando aparecen orientaciones de decisión evaluativas y cuando se posee información y capacidades.

Adicionalmente hemos construido una matriz a partir de los dos parámetros utilizados como indicadores del desempeño, la tasa de reemplazo y el monto de la pensión (establecido como proporción de la pensión máxima con aporte solidario, PMAS) que permite identificar segmentos de protección en la vejez y el número de personas asociado a cada uno. El primero tiene relación con la proporción del salario que representa la pensión obtenida y los cortes establecidos se definieron desde un punto de vista más bien estadístico, separando a las personas entre quienes están sobre el $50 \%$ de la tasa de reemplazo y quienes están bajo esa medida. Por otra parte, y desde una perspectiva más sustantiva, distinguir entre quienes están por sobre la PMAS y por debajo de ella permite hacerse una idea de quienes el mismo sistema considera necesitados de apoyo complementario para aumentar su protección en la vejez a través de subsidios estatales. Con ambos parámetros se ha obtenido la siguiente tabla de doble entrada: 
Cuadro 1: Segmentos de protección en la vejez

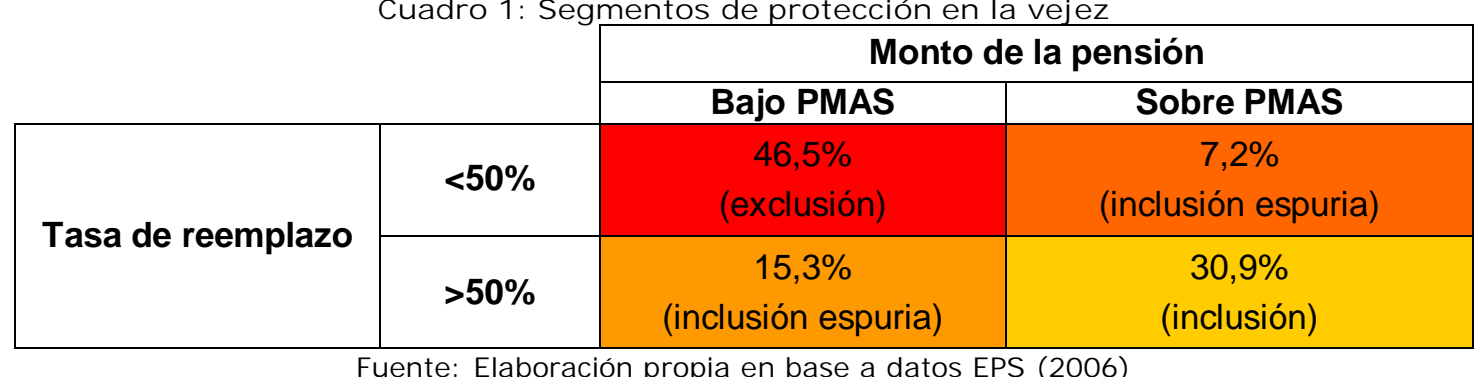

Si se suman los cuadrantes asociados a estados de exclusión y de inclusión espuria vemos que cerca de un $70 \%$ de los pensionados se encuentra en una situación de vulnerabilidad respecto de su protección en la vejez.

El gráfico 15 muestra como se distribuye la clasificación anterior por sexo y ocupación, siendo evidente que existe una alta diferenciación. La más relevante es la que separa a hombres y mujeres, destacándose la menor protección que tienen las mujeres en su vejez. Por otro lado, vuelve a destacarse el hecho de que las ocupaciones con menor calificación y aquellas que se realizan de manera independiente obtienen peores resultados en términos de la protección que pueden obtener al salir del mercado del trabajo. 


\section{Gráfico 15: Distribución de la población según segmentos de protección en la vejez}

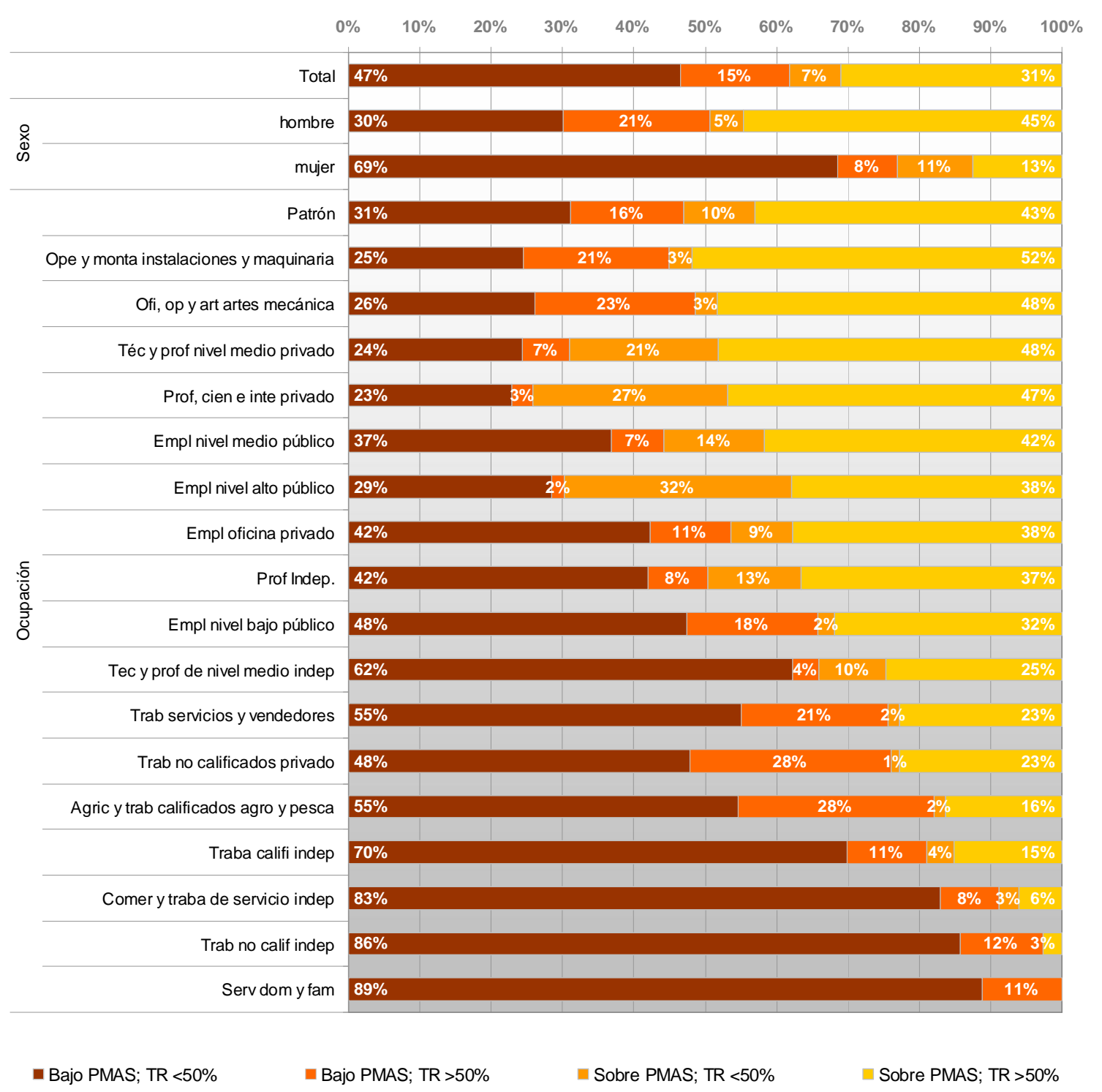

Fuente: Elaboración propia en base a datos EPS (2006)

\section{CONCLUSI ONES}

De la investigación realizada podemos sacar una serie de conclusiones de política. Por una parte, los resultados muestran un desempeño segmentado del sistema de pensiones chileno debido a que este ofrece probabilidades de protección social que no consideran el comportamiento de su principal determinante: el desempeño del mercado del trabajo. Las características del mercado del trabajo en Chile generan capacidades contributivas diferenciadas para distintos grupos de trabajadores según su ocupación y su nivel educacional, además de la evidente diferenciación en el acceso a 
niveles de protección que produce el sexo. En términos analíticos podemos decir que en su diseño institucional, el sistema de pensiones incorpora hipótesis sobre el comportamiento del mercado del trabajo que no llegan a cumplirse en la realidad. De este modo, al ofrecer una protección homogénea y basada estrictamente en la capacidad contributiva de cada trabajador, mantiene los segmentos del mercado del trabajo como segmentos de protección para la vejez, perpetuando así desigualdades estructurales asociadas a los niveles de educación y las ocupaciones que logran alcanzar distintos grupos de la población y a la diferenciación de roles al interior del hogar. Esto es contrario a la tesis de una completa diferenciación funcional en la sociedad chilena, pudiéndose apreciar la generación de estructuras de exclusión (y de inclusión) yuxtapuestas que afectan sistemáticamente a determinados grupos de la población. Al igual como ocurre, por ejemplo, con el sistema educativo, se generan amplias zonas de exclusión y de inclusión espuria signadas por situaciones de vulnerabilidad que llevan a anticipar la necesidad de intervención del Estado bajo la forma de pensiones básicas y aportes solidarios.

La utilización de la noción de desempeño institucional que hemos desarrollado como marco analítico nos ha permitido, en este contexto, establecer zonas donde se puede observar los grados de protección social en la vejez a los que acceden distintos grupos de personas, identificando aquellas zonas de menor protección y quienes se ubican en ellas. En este sentido, dado el comportamiento del mercado del trabajo en Chile, la solución en términos previsionales pareciera requerir un tratamiento particular de determinadas categorías de trabajadores. Este parece ser el caso urgente de los trabajadores y trabajadoras domésticos y los familiares no remunerados, así como también de distintas categorías de trabajadores independientes y empleados en actividades del comercio y agrícolas. I gualmente importantes resulta tomar algunas medidas para solucionar los problemas de una serie de categorías laborales que muestran bajas tasas de reemplazo, y por tanto, altos niveles de vulnerabilidad en la medida que la entrada al período de inactividad supondría una fuerte merma en el ingreso y en los niveles de consumo, como es el caso de los empleados de nivel bajo del sector público y empleados de oficina del sector privado por nombrar algunos.

Por otro lado, si bien se ha visto que distintas estrategias individuales generan variaciones en el desempeño del sistema, su descomposición en 3 momentos (capacidades, información y toma de decisiones) nos permite decir algo más respecto de los supuestos conductuales que incorpora el sistema. Lo más relevante nos parece que se refleja en el bajísimo porcentaje de personas que toma sus decisiones racionalmente tal como lo prevé el sistema. En la mayoría de los casos, aun teniendo las capacidades y la información necesarias, las decisiones se toman a partir de una mezcla de elementos en los que frecuentemente intervienen elementos afectivos o no racionales y también condicionamientos externos de varios tipos. De este modo, no sólo las hipótesis de racionalidad de los agentes bajo las cuales opera el sistema no se cumplen, sino que además puede esperarse que las modificaciones típicas que son propuestas como reformas para mejorar su desempeño (básicamente aumentar los niveles de información que poseen los individuos) no den los resultados esperados en términos de una mejor toma de decisiones en materia previsional. En este sentido, si bien quienes presentan orientaciones evaluativas tienden a lograr mayores niveles de protección, estas parecieran responder a la forma de tomar las decisiones de grupos específicos, distintas de las estrategias llevadas a cabo por otros grupos para solucionar los problemas de protección social en la vejez.

Nos parece, además, que la forma de operacionalizar los elementos de racionalidad y los resultados arrojados generan contribuciones al ámbito del análisis y diseño de 
políticas públicas que van más allá de las consecuencias concretas para el sistema de pensiones. Esto especialmente en el contexto de una norma del bienestar como la individualista/liberal que privilegia políticas de inclusión social en que el componente de toma de decisiones individuales (vinculada a una racionalidad sustantiva) cumple un papel preeminente en las probabilidades de inclusión que ofrecen distintos programas y mecanismos de protección social. $\underline{\mathbf{R M}}$

\section{Bibliografía}

1. ARNOLD, MARCELO. 2008. "Imágenes de la complejidad: diferenciación, integración y exclusión social", ponencia presentada al Encuentro internacional Niklas Luhmann a diez años: el de observar una sociedad compleja, Santiago de Chile, 8 y 9 de octubre, Goethe Institut, DAAD, Universidad Católica de Chile, Universidad Alberto Hurtado, Universidad de Chile.

2. BARR. NICHOLAS. 2000. Reforming pensions: myths, truths, and policy choices. IMF Working Paper WP/00/139, Fondo Monetario Internacional (FMI).

3. BARR, NICHOLAS Y PETER DIAMOND. 2006. "The economics of pensions" Oxford Review of Economic Policy. vol. 22, no 1

4. BERSTEIN, SOLANGE Y JOSÉ LUIS RUIZ. 2005. "Sensibilidad de la demanda con consumidores desinformados: el caso de las AFP en Chile" Serie Documentos de Trabajo, no 4, Santiago: Superintendencia de AFP (SAFP), Gobierno de Chile.

5. BERSTEIN, SOLANGE, GUILLERMO LARRAÍN Y FRANCISCO PINO. 2005. "Cobertura, densidad y pensiones en Chile: proyecciones a 20 años plazo" Serie Documentos de trabajo, n12, Santiago: Superintendencia de AFP (SAFP), Gobierno de Chile.

6. BERSTEIN, SOLANGE Y CAROLINA CABRITA. 2006. "Los determinantes de la elección de AFP en chile: nueva evidencia a partir de datos individuales" Serie Documentos de Trabajo, no19 Santiago: Superintendencia de AFP (SAFP), Gobierno de Chile.

7. BERTRANOU, FABIO (ed.). 2001. “Cobertura previsional en Argentina, Brasil y Chile". Santiago: Oficina Internacional del Trabajo (OIT)

8. Taboral en América Latina" en Protección social y mercado laboral. F. Bertranou (ed.). Santiago: Oficina Internacional del Trabajo (OIT)

9. BOLTANSKI, LUC Y LAURENT THEVENOT. 1991. De la justification. Les économies de la grandeur. Paris: Gallimard

10. BOYER, ROBERT. 2006. “L'Hétérogénéité des relations salariales contempôraines et ses conséquences, ponencia presentada al coloquio "Las ciencias sociales en transformación", 3-6 Mayo 2006, Paris-Jourdan Sciences Economiques - École Normale Superieur, París.

11. _2007. Crisis y regímenes de crecimiento. Una introducción a la teoría de la regulación. Buenos Aires: Miño y Dávila/CEI L PIETTE CONICET.

12. CASTEL, ROBERT. 2006. La metamorfosis de la cuestión social, Buenos Aires: Paidós.

13. CENDA - INP. 2005. Proyección previsional de la población afiliada y cotizante a las AFP, Santiago: Centro de Estudios Nacionales de Desarrollo Alternativo (CENDA)/Instituto de Normalización Previsional (INP).

14. CEPAL. 2006. La protección social de cara al futuro: acceso, financiamiento y solidaridad, trigésimo primer período de sesiones de la CEPAL, Montevideo, 20 al 24 de marzo de 2006, Santiago: Comisión Económica para América Latina y el Caribe. 
15. CONSEJO ASESOR PRESIDENCIAL PARA LA REFORMA PREVISIONAL.. 2006. Informe Final Volumen 1: Diagnóstico y propuesta de reforma. Santiago.

16. DEQUECH, DAVID. 2001. "Bounded rationality, institutions and uncertainty" J ournal of Economic Issues, vol. XXXV, no4, diciembre.

17. ESPING-ANDERSEN, GÖSTA. 2000. Fundamentos Sociales de las Economías Postindustriales, Barcelona: Ariel.

18. GIDDENS, ANTHONY. 1998. La Constitución de la sociedad. Bases para una teoría de la estructuración, Buenos Aires: Amorrortu.

19. GORA, MAREK Y EDWARD PALMER. 2004. Shifting perspectives in pensions, IZA Discussion paper no. 1369, Bonn: Institute for the Study of Labor.

20. HERRERA, MANUEL Y PEDRO CASTÓN. 2003. Las políticas sociales en las sociedades complejas, Barcelona: Ariel.

21. HOLLINGSWORTH, J. ROGERS Y ROBERT BOYER. 1997. “Coordination of economic actors and social systems of production" en Contemporary capitalism. The Embeddedness of institutions, J.R. Hollingsworth y R. Boyer (eds.), Nueva York: Cambridge University Press, 1997.

22. JAGD, SÖREN. 2003. The notion of Convention in French Economics of Conventions, Paper for the colloque: Conventions et institutions: Approfondissements Theoriques et contributions au Debat Politiques, La Defense, París, diciembre de 2003.

23. INP - CENDA. 2005. Proyección previsional de la población afiliada y cotizante a las AFP, Santiago: Centro de Estudios Nacionales de Desarrollo Alternativo (CENDA)/Instituto de Normalización Previsional (INP).

24. KAZTMAN, RUBÉN Y CARLOS FILGUEIRA. 1999. Marco conceptual sobre vulnerabilidades, activos y estructura de oportunidades, LC/MVD/R.176.Rev.1, Montevideo: CEPAL.

25. LECHNER, NORBERT. 1997. "Tres formas de coordinación social" Revista de la CEPAL, no 61, Santiago: Abril

26. LUHMANN, NIKLAS. 1996. Introducción a la teoría de sistemas, Barcelona: Anthropos. caps. 11 y 13

27. modernidad, N. Luhmann, Buenos Aires/Barcelona: Paidós.

28. Trotta.

29. _._- 1998b. Sistemas sociales, Barcelona/México/Bogotá: Ānthropos/Universidad I beroamericana/CEJ A.

30. _.__ 1998c. "La diferenciación de la sociedad" en Complejidad y modernidad. De la unidad a la diferencia, N. Luhmann, Madrid: Trotta.

31. 2002. La teoría política en el estado de bienestar, Madrid: Alianza.

32. MARINAKIS, ANDRÉS. 2006. "La rigidez de los salarios en Chile" Revista de la CEPAL, N $\mathrm{N}^{\circ}$ 90: 135- 150.

33.

34. MAYNTZ, RENATE. 1998. "Nuevos desafíos de la teoría de Governance" Revista Instituciones y Desarrollo, no7: Barcelona, 2000.

35. MESA-LAGO, CARMELO. 2004. "Las reformas de pensiones en América latina y su impacto en los principios de la seguridad social" Serie financiamiento de desarrollo, no 144, Santiago: Comisión Económica para América Latina y el Caribe (CEPAL).

36. MINTRAB. 2003. Observatorio Laboral, no 3. Publicación periódica del Ministerio del Trabajo y Previsión Social, Gobierno de Chile.

37. NORTH, DOUGLASS C. 2006. Instituciones, Cambio Institucional y Desempeño Económico, México: Fondo de Cultura Económica. 
38. PINO, FRANCISCO. 2005. "Retiros Programados y nuevas tablas de mortalidad" Serie Notas técnicas №1. Santiago: Superintendencia de Administradoras de Fondos de Pensiones

39. POLANYI, KARL. 1957. "The economy as instituted process" en The Sociology of Economic Life. R. Swedberg y M. Granovetter (eds.), Boulder: Westview Press, 1992.

40.

2003. La Gran Transformación. Los orígenes políticos y económicos de nuestro tiempo, México: Fondo de Cultura Económica.

41. SAFP. 2007. El sistema de pensiones chileno. Santiago: Superintendencia de Administradoras de Fondos de Pensiones.

42. SIMON, HERBERT A. 1982. Models of bounded rationality, vol II: Behavioral Economics and Bussines Organization, Cambridge-Massachusetts: The Massachusetts Institute for Technology (MIT) Press.

43. SUNDÉN, ANNIKA. 2005. "How much do people need to know about their pensions and what do they know?" en Pension Reform through NDCs: Issues and Prospects for Non-Financial Defined Contribution Schemes, R. Holzmann y E. Palmer (eds.) Washington D.C: Banco Mundial, 2005.

44. THÉVENOT, LAURENT. 1989. "Equilibrio y racionalidad en un universo complejo" en Economía de las convenciones, F. Eymard-Duvernay (comp.), Buenos Aires: Asociación Trabajo y Sociedad, 1994.

45. UTHOFF, ANDRAS. 2006. "Transformaciones en el mercado del trabajo e implicaciones para los sistemas de pensiones" en Efectos Económicos de los Sistemas de Pensiones, R. Ham Chande y B. Ramírez López (coords.), México: Plaza y Valdés/El Colegio de la Frontera Norte.

46. _._-_ 2006. "Brecha del Estado de Bienestar y reformas a los sistemas de pensiones en América Latina y el Caribe". Serie Políticas Sociales n.117. Santiago de Chile: CEPAL.

47. WEBER, MAX. 2002. Economía y Sociedad. México: Fondo de Cultura Económica.

48. WILLKE, HELMUT. 1993. "Formas de autoorientación de la sociedad" en Teoría de sistemas de las sociedades desarrolladas. Dinámica y riesgo de la autoorganización social moderna", cap. 4, H. Willke, (traducción de Aldo Mascareño), München: Juventa Verlag.

49. 1995. "La transformación de la democracia como modelo de orientación de làs sociedades complejas" Estudios Públicos. no 102, otoño de 2006.

50. ZURBRIGGEN, CRISTINA. 2006. "EI institucionalismo centrado en los actores: una perspectiva analítica en el estudio de las políticas públicas". Ciencia Política. 26, 1: 67-83

\section{Notas}

${ }^{1}$ Cf. Banco Mundial (1994): Averting the old age crisis: policies to protect the old and promote growth, Washington D.C.

2 Sobre la carga fiscal asociada a las transiciones desde un sistema de reparto a otro de capitalización individual en varios países de América Latina véase de Carmelo Mesa-Lago. (2000). "Estudio comparativo de los costos fiscales en la transición de ocho reformas de pensiones en América Latina" Serie financiamiento del desarrollo, $n^{\circ}$ 53, Santiago: CEPAL; En CEPAL (2006) se encuentra además una breve descripción tanto de los problemas de financiamiento como de concentración del mercado de administradoras privadas. Sobre los problemas que la crisis financiera comenzada en agosto de 2007 y desatada en octubre de 2008 ha traído a la gestión de los fondos de pensiones véase los trabajos de CENDA en www.cendachile.cl

${ }^{3}$ Vale la pena revisar la discusión que se dio en el seno del Consejo Asesor para la Reforma Previsional y los argumentos más frecuentes. Ver http://www.consejoreformaprevisional.cl

${ }^{4}$ Es interesante, en el contexto de una teoría de la elección racional, lo que propone Elster respecto del rol que juegan las normas al permitir juegos repetitivos que relajan, de alguna u otra manera, la presión que se ejerce sobre los propios agentes en cada nueva interacción cuando se los entiende desde una racionalidad 
sustantiva e incluso una racionalidad estratégica. Ver de Jon Elster (1991): El cemento de la sociedad, Barcelona: Gedisa.

${ }^{5}$ A nivel teórico parecen claros los mayores rendimientos para la observación que supone la incorporación de la distinción inclusión/exclusión al incorporar la idea de que las situaciones de inclusión social generan necesariamente espacios de exclusión pues se entienden siempre como una operación de selección de una diferencia. En este contexto es interesante el concepto que propone Castel (2006) de "desafiliación" que alude a entender la exclusión como un proceso. De este modo se mantiene una relación dinámica entre inclusión y exclusión enfatizando la dependencia o subsidiariedad del lado de la exclusión al de la inclusión, que obliga al mismo tiempo a tener en cuenta la imposibilidad de una inclusión total o completa, y por tanto, asumir que cada vez que se incluye se excluye al mismo tiempo. Resulta atractivo, además, observar lo que sucede cuando se realiza la "re-entry de la forma en la forma", es decir, la repetición de la distinción inclusión/exclusión en cada uno de los lados. Esto permite observar nuevos espacios, tanto de exclusión como de inclusión difíciles de aprehender cuando se utilizan las categorías tradicionales, lo que permite dar cuenta de la complejidad de las situaciones de inclusión y exclusión en las sociedades contemporáneas y que puede ser sumamente fructífero para el diseño de políticas y de programas sociales. Sobre esto último véase el diagrama propuesto más adelante.

${ }^{6}$ Vale aclarar que desde una perspectiva sistémica nos parece difícil hablar estrictamente de "sistemas de protección social" tal como se denominan en la literatura especializada, debido a que estos no constituyen sistemas propiamente tal. Hemos identificado al menos dos motivos para ello: en primer lugar, no poseen una clausura operativa, esto es, no existe una delimitación clara entre sistema y entorno que permita identificar un conjunto de comunicaciones autorreferenciales, lo que a su vez tiene relación con el hecho de no poder distinguir entre autorreferencia y referencia externa. Por otro lado, estos operan de modo general con el código inclusión/exclusión que es una forma generalizada para el conjunto de la sociedad, es decir, no poseen un código de valor que les sea propio, como por ejemplo bueno/malo para la moral, justo/injusto para el sistema jurídico, verdad/no verdad para el sistema científico, etc. Si bien para efectos analíticos hemos preferido utilizar el concepto de "mecanismos" de protección social, dada la extensión de la utilización del concepto de "sistemas de pensiones" se ha preferido mantener esta denominación con las salvedades expuestas.

${ }^{7}$ Vale la pena revisar, por ejemplo, lo que ocurría con las poor houses que constituyeron una de las formas típicas de protección social en el siglo XIX. Respecto de ellas Bauman apunta : "al limitar la asistencia a lo que se pudiera conseguir dentro de esos sórdidos y miserables asilos, se lograba que el 'certificado de pobreza' fuera innecesario o, mejor, que los pobres se lo otorgaran a sí mismos: quien aceptara ser encerrado en un asilo para pobres por cierto que no debía contar con otra forma de supervivencia", Bauman, Zygmunt. 2008. Trabajo, consumismo y nuevos pobres. Barcelona: GEDISA. véase también sobre lo mismo Polanyi (2003) y Castel (2006).

8 "For most problems that Man encounters in the real world, no procedure that he can carry out with his information processing equipment will enable him to discover the optimal solution, even when the notion of 'optimum' is well defined. There is no logical reason why this need be so; it is simply a rather obvious empirical fact about the world we live in- a fact about the relation between the enormous complexity of that world and the modest information-processing capabilities with which Man is endowed (...). We can expect substantive rationality only in situations that are sufficiently simple as to be transparent to his mind. In all other situations, we must expect that the mind will use such imperfect information as it has, will simplify and represent the situation as it can, and will make such calculations as are within its powers. We cannot expect to predict what it will do in such situations unless we know what information it has, what forms of representation it prefers, and what algorithms are available to it." (Simon, 1982: 439; 430).

9 Ver al respecto el sugerente texto de Robert Salais, Nicolas Bavarez y Bénedicte Reynaud (1999) L'invention du chômage, Paris: PUF, donde investigan los origenes y contenido de la convención que define el desempleo en la sociedad moderna. Respecto de cómo las convenciones pueden dar origen a formas típicas de empresas o mundos productivos, ver Michael Storper y Robert Salais (1997): Worlds of production. the action frameworks of the economy, Harvard: Harvard University Press, También el trabajo de Robert Boyer junto a Michel Freyssenet (2001): Los modelos productivos, Buenos Aires: Trabajo y Sociedad, CEIL-PIETTE, IADE, Lumen-Humanitas. Sobre los mundos productivos y los distintos órdenes institucionales en que estos se inscriben ha surgido una nutrida literatura que habla de la existencia de "capitalismos" haciendo énfasis en la identidad que determinadas macro instituciones confieren a una sociedad histórica. ver por ejemplo, David Soskice y Peter Hall (eds.) (2001): Varieties of capitalism: the institutional foundations of comparative advantage. Oxford: Oxford University Press; Bruno Amable (2004): The diversity of modern capitalism, Oxford: Oxford Univesity Press.

${ }^{10}$ Esto es particularmente interesante de observar a la luz de estudios que muestran la alta concentración en que dichos fondos están colocados - es decir que no seguirían el patrón racional que supondría una "diversificación del riesgo"-, frecuentemente invertidos en empresas del mismo holding a que pertenece la administradora. Ello se hace más pertinente aún en el contexto de la actual crisis financiera y el manejo del riesgo asociado a las inversiones. Véase al respecto los trabajos de CENDA (2007): "Resultados para sus Afiliados de las AFP y Compañías de Seguros Relacionadas con la Previsión. 1982-2006" y de octubre de

Revista Mad. N²0, Mayo de 2009. Departamento de Antropología. Universidad de Chile http://www. revistamad.uchile.cl/20/madariaga_01.pdf 
Nuevas aproximaciones para el análisis de sistemas de protección social: La noción de desempeño institucional y su aplicación al sistema de pensiones chileno

2008 "Variación de los Fondos de Pensiones AFP desde el Inicio de la Crisis Financiera Mundial" disponibles en http://www.cendachile.cl

11 Ambos se encuentran incluidos en las convenciones de la OIT como indicadores de los mínimos de bienestar que los sistemas de pensiones deben asegurar. Ver el Convenio 128 sobre prestaciones de invalidez, vejez y sobrevivientes. Este Convenio adoptado el año 1967 viene a agrupar una serie de proposiciones específicas respecto de la suficiencia de los seguros sociales que comienzan a ser emitidas desde el año 1933.

12 Por ejemplo, la medición del indicador tradicional de cobertura poblacional para el año 2001 arrojaba una cifra de población asegurada imposible: 108\% (MINTRAB, 2003). A partir de ello se han hecho algunos intentos por adecuar el indicador de cobertura poblacional de manera de hacerlo más preciso, lo que ha dado origen a nuevos conceptos de cobertura, que arrojan distintas cifras según la base de cálculo de la fórmula. De este modo a parte del indicador de cobertura poblacional tradicional ("cobertura estadística"), encontramos el de "cobertura efectiva", que capta la cobertura del seguro sobre quienes han cotizado el último mes por contraste con quienes están inscritos pero no efectúan aportes, el de "cobertura ocupacional" que reduce la base de la medición desde la fuerza de trabajo hacia sólo los ocupados, y la "cobertura de pensiones" que intenta aprehender el nivel de cobertura del seguro entre los adultos mayores (MINTRAB, 2003). Estas nuevas medidas de cobertura, sin embargo, aumentan la complejidad de la medición antes que reducirla, pues se torna difícil definir cuál de ellas constituye el indicador adecuado.

13 Para la elaboración de un modelo como este hemos utilizado la Encuesta de Protección Social (EPS) del año 2006. A falta de otro instrumento de observación de las acciones efectivamente llevadas a cabo por los agentes para la obtención de una pensión, se consideró como un indicador de las estrategias individuales las respuestas que los entrevistados dieron en la encuesta respecto de: información sobre el sistema de pensiones, capacidades cognitivas asociadas a operaciones comunes requeridas para tomar decisiones en el sistema, y para observar las orientaciones de decisión se consideraron aquellas preguntas en que los entrevistados debían dar razones de las decisiones tomadas en distintos parámetros del sistema de pensiones cuyas alternativas determinaran el monto de las pensiones a recibir a futuro. Para las variables "información sobre el sistema de pensiones" y "capacidades cognitivas de procesamiento de información previsional" se generaron 4 categorías a partir de los puntajes asignados a cada caso según sus respuestas a las preguntas seleccionadas: nula, insuficiente, suficiente, satisfactoria. Para las orientaciones de decisión se clasificaron las respuestas dadas en función de 3 distinciones: 1) en primer lugar se distinguió según las decisiones fueran tomadas a partir de consideraciones individuales, o en función de elementos externos (autónomas/heterónomas), 2) dentro de las primeras, se subdividió a su vez según se ponderara o no los medios y fines en estricta relación con el objetivo de obtener una mayor pensión (evaluativas/no evaluativas) y a su vez cada una de ellas según las características de la toma de decisiones

${ }^{14}$ Véase un ejercicio similar en Uthoff (2006). También OIT (2004): Panorama laboral 2003, Lima.

15 Véase en Berstein y otros (2005) el anexo donde se detallan los supuestos utilizados en cuatro estudios clásicos sobre el sistema de pensiones. Si bien estos se centran en establecer la cobertura, entendida como cobertura poblacional, también deben proyectar el monto de las pensiones esperadas

${ }^{16}$ Como parámetro de renta del cálculo, se decidió tomar la proyección del salario final del cotizante, a partir del salario promedio del periodo de medición.

${ }^{17}$ Las tasas de reemplazo están referidas al último sueldo proyectado.

18 Las ocupaciones incluidas en este grupo son el servicio doméstico y el familiar no remunerado, los trabajadores no calificados independientes, los comerciantes y trabajadores del sector servicio independiente, trabajadores calificados independientes, los técnicos y profesionales de nivel medio independientes, Profesionales independientes, empleados de nivel bajo del sector público y Agricultores y trabajadores calificados del agro y la pesca.

${ }^{19}$ Es decir agrupando las dos primeras categorías de menor posesión de información vs. las 2 categorías de mayor posesión de información.

${ }^{20} \mathrm{En}$ el caso de personas que aparecen con densidad de cotizaciones con valor $0 \%$, se trata de personas que no muestran cotizaciones en el periodo observado, pero si están afiliados al sistema de AFP.

${ }^{21}$ Homals, $95.1 \%$ de la varianza explicada. 